Article

\title{
Review on Lane Detection and Tracking Algorithms of Advanced Driver Assistance System
}

\author{
Swapnil Waykole, Nirajan Shiwakoti *(D) and Peter Stasinopoulos \\ School of Engineering, RMIT University, Melbourne, VIC 3000, Australia; s3706835@student.rmit.edu.au (S.W.); \\ peter.stasinopoulos@rmit.edu.au (P.S.) \\ * Correspondence: nirajan.shiwakoti@rmit.edu.au
}

Citation: Waykole, S.; Shiwakoti, N.; Stasinopoulos, P. Review on Lane Detection and Tracking Algorithms of Advanced Driver Assistance System. Sustainability 2021, 13, 11417. https:/ / doi.org/10.3390/su132011417

Academic Editors: Young-Ji Byon, Feng Chen and Meng Guo

Received: 1 September 2021

Accepted: 9 October 2021

Published: 15 October 2021

Publisher's Note: MDPI stays neutral with regard to jurisdictional claims in published maps and institutional affiliations.

Copyright: (C) 2021 by the authors. Licensee MDPI, Basel, Switzerland. This article is an open access article distributed under the terms and conditions of the Creative Commons Attribution (CC BY) license (https:// creativecommons.org/licenses/by/ $4.0 /)$.

\begin{abstract}
Autonomous vehicles and advanced driver assistance systems are predicted to provide higher safety and reduce fuel and energy consumption and road traffic emissions. Lane detection and tracking are the advanced key features of the advanced driver assistance system. Lane detection is the process of detecting white lines on the roads. Lane tracking is the process of assisting the vehicle to remain in the desired path, and it controls the motion model by using previously detected lane markers. There are limited studies in the literature that provide state-of-art findings in this area. This study reviews previous studies on lane detection and tracking algorithms by performing a comparative qualitative analysis of algorithms to identify gaps in knowledge. It also summarizes some of the key data sets used for testing algorithms and metrics used to evaluate the algorithms. It is found that complex road geometries such as clothoid roads are less investigated, with many studies focused on straight roads. The complexity of lane detection and tracking is compounded by the challenging weather conditions, vision (camera) quality, unclear line-markings and unpaved roads. Further, occlusion due to overtaking vehicles, high-speed and high illumination effects also pose a challenge. The majority of the studies have used custom based data sets for model testing. As this field continues to grow, especially with the development of fully autonomous vehicles in the near future, it is expected that in future, more reliable and robust lane detection and tracking algorithms will be developed and tested with real-time data sets.
\end{abstract}

Keywords: lane detection; lane tracking system; sensors; advanced driver assistance system (ADAS); lane departure warning system

\section{Introduction}

Autonomous passenger vehicles are a direct implementation of transportation-related autonomous robotics research. They are also known as self-driving vehicles or driverless vehicles. Shakey the robot (1966-1972) is the first autonomous mobile robot that has been documented [1]. It was developed by Stanford Research Institute's Artificial Intelligence Centre and was capable of detecting the environment, thinking, planning, and navigation. In basic settings, vision-based lane tracking and obstacle avoidance sparked interest in autonomous vehicles [2]. In the early 1990s, The Royal Armament Research and Development Establishment in the United Kingdom created two vehicles for obstacle-free navigation on and off the road [3]. In the United States, the first operations of autonomous driving in realistic settings dates back to Carnegie Mellon University's NavLab in the early 1990s [4]. The vehicle developed by NavLab was operated at very low speeds due to the limited computational power available at the time. Early US research projects also included the California PATH project, which developed the automated highway [5]. Vehicle steering was automated with manual longitudinal control in the "No Hands Across America" project [6]. In early 2000, CyberCars, one of several European projects began developing technologies based on automated transport [7]. The announcement of the defence advanced research projects agency (DARPA) grand challenge in 2003 generated research interest in 
autonomous cars. Following that, in 2006, the DARPA urban challenge was performed in a controlled situation with a variety of autonomous and human-operated vehicles. Since then, many manufactures, including Audi, BMW, Bosch, Ford, GM, Lexus, Mercedes, Nissan, Tesla, Volkswagen, Volvo and Google, have launched self-driving vehicle projects in collaboration with universities [8]. Google's self-driving car has experimented and travelled 500 thousand kilometres and has begun building prototypes of its own cars [9]. A completely autonomous vehicle would be expected to drive to a chosen location without any expectation of shared control with the driver, including safety-critical tasks.

The performance of lane detection and tracking depends on the well-developed roads and their lane markings, so smart cities are also a prominent factor in autonomous vehicle research. The idea of a smart city is often linked with an eco-city or a sustainable city, both of which seek to enhance the quality of municipal services while lowering their costs. Smart cities' primary goal is to balance technological innovation with the economic, social, and environmental problems that tomorrow's cities face. The greater closeness between government and people is required in smart cities that embrace the circular economy's concepts [10]. The way materials and goods flow around people and their demands will alter, as will the structure of cities. Several car manufacturers such as Tesla and Audi have already launched autonomous vehicle marketing for private use. Soon, society will be influenced by autonomous vehicles' spread to urban transport systems [11]. The development of smart cities with the introduction of connected and autonomous vehicles could potentially transform cities and guide long-term urban planning [10].

Autonomous vehicles and Advanced Driver Assistance Systems (ADAS) are predicted to provide a higher degree of safety and reduce fuel and energy consumption and road traffic emissions. ADAS is implemented for safe and efficient driving, which has many driver assistance features such as warning drivers about forwarding collision warning or safe lane change [12]. Research shows that most accidents occur because of driver errors, and the ADAS can reduce the accidents and workload of the driver. If there is a likelihood of an accident, ADAS can take the necessary action to avoid it [13]. Lane departure warning (LDW), which utilizes lane detection and tracking algorithms, is an essential feature of the ADAS. The LDW warns the driver when a vehicle crosses white lane lines unintentionally and controls the vehicle by bringing it back into the desired safe path. Three types of approaches for lane detection are usually discussed in the existing literature: learningbased approach, features-based approach, and model-based approach [13-18] (detailed analysis are presented in Section 3.2). Many challenges and issues have been highlighted in the literature regarding the LDW systems, such as visibility conditions change, variation in images, and lane appearance diversity [17]. Since different countries have used various lane markers, there is a challenge for lane detection and tracking to solve the problems.

\subsection{Objectives and Scope of the Study}

There are limited studies that provide state-of-art lane detection and tracking algorithms for ADAS. This review paper aims to comprehensively review the previous literature on lane detection and tracking for ADAS and identify gaps in knowledge for future research. The report compares different lane detection and tracking algorithms and analyses different datasets used to verify the algorithms and metrics used to evaluate the algorithms. Specifically, the review identifies and classifies the existing lane detection and tracking algorithms under three themes: features-based, learning-based and model-based, which provides a systematic approach towards understanding the key characteristics of lane detection and tracking algorithms in the literature. Some patented works by vehicle manufacturers under these three categories are also reviewed to acknowledge growing commercialisation interests in this field of study. However, given the large number of patents by educational institutions, research groups and vehicle manufacturers, a detailed review of patented works is outside the scope of this study. This systematic review is expected to assist researchers working in this area by delivering current advancements 
made in lane detection and tracking for ADAS and the challenges to overcome in the future for robust lane detection and tracking systems.

The structure of the paper is as follows. Section 2 provides an overview of the methodology adopted for the literature review. It is then followed by a detailed literature review that includes a brief introduction to sensors used in the ADAS, an analysis of the existing literature on lane detection and tracking algorithms. Section 4 presents the discussions followed by conclusions in Section 5 .

\section{Methodology}

Literature was gathered from the electronic database. The database included "ISI Web of Science", "Science Direct" "Scopus" "Google Scholar" and "IEEE Xplore". The keywords used for the search were "Lane detection algorithms", "Lane tracking algorithms", "Lane departure warning algorithms", "Advanced driver assistance system", "Lane change tracking", "Vehicle tracking", Vehicle tracking sensors", and "Automated lane change" or a combination of these words (Figure 1). We also searched for patented works. Patents published from 2006 to 2020 were also searched using the term "Lane detection and tracking," "Lane departure warning," and "Advance driver assistance system" using the "Google scholar" and "PubMed". As mentioned in Section 1.1, the objective of patents search is to acknowledge growing commercialisation interests in this field of study rather than a detailed review of the patented works. As such, only a sample of patents works from vehicle manufacturers was discussed. The period studied for the literature is the past two decades, as lane tracking and detection is an emerging field that has gained momentum post-2000. English language-based publications were only considered for the review as they are widely accessible to global readers. Relevant publications further improved the search procedure in the reference lists available in the collected literature. The lane detection and tracking algorithms were investigated under three approaches that have been commonly referred to in the literature (Features based, learning-based and model-based as shown in Figure 1). The existing databases were analyzed to identify the availability of datasets for future research. The lane detection criteria, calculation of the detection rate and accuracy of the algorithms that have been adopted in the literature are also reviewed.

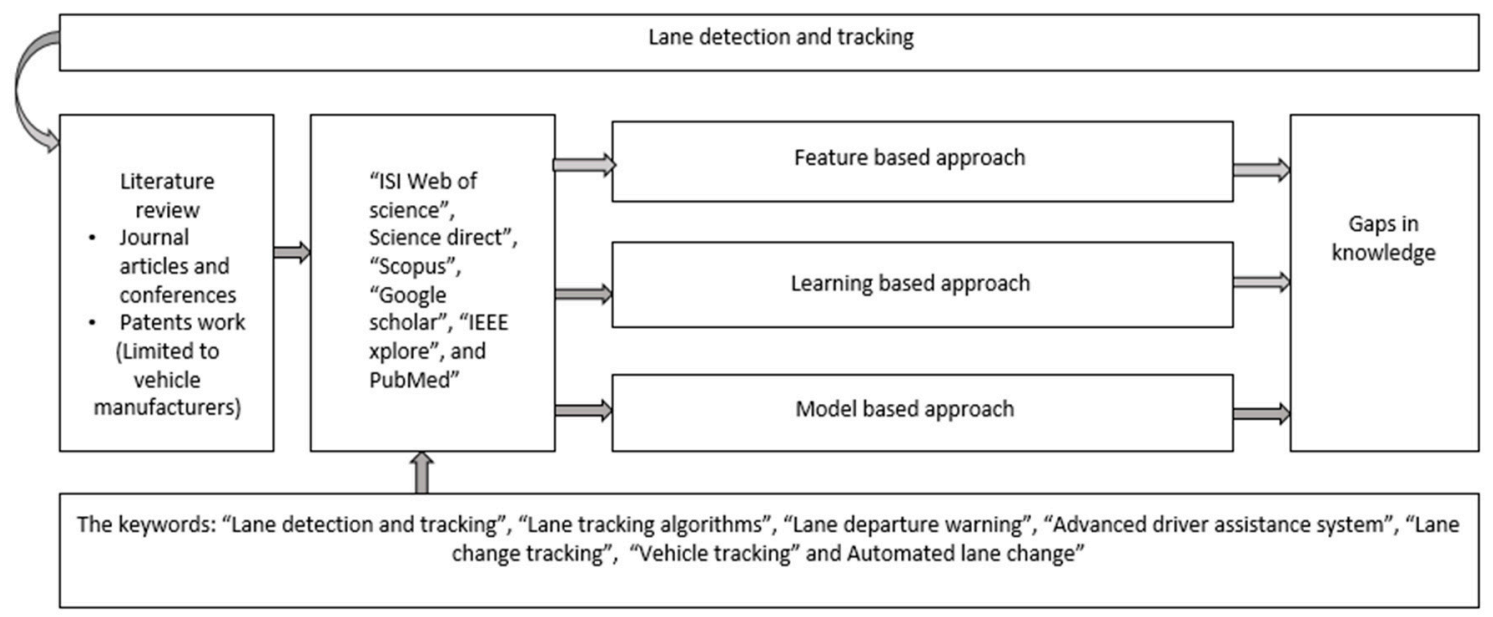

Figure 1. Flowchart showing the methodology adopted for the review.

\section{Literature Review}

A comparison of the different sensors used in ADAS is presented first. It is then followed up with an in-depth review of algorithms used for lane detection and tracking, including the patented works. 


\subsection{Sensors Used in the ADAS}

ADAS deploy different sensors fusion systems to guide the vehicle (Figure 2). In the literature, three types of sensors have been identified that are used in the ADAS, which are, Light Amplification by Stimulated Emission of Radiation (LASER) based sensors, Radio Detection And Ranging (RADAR) based sensors and vision-based sensors as described below. Table 1 shows the Strengths, Weaknesses, Opportunities, and Threats (SWOT) analysis of LASER, RADAR and vision-based sensors.se

Table 1. SWOT analysis of sensors that are used in ADAS.

\begin{tabular}{|c|c|c|c|c|c|c|c|c|c|}
\hline $\begin{array}{l}\text { Type of } \\
\text { Sensors }\end{array}$ & $\begin{array}{l}\text { Relative } \\
\text { Velocity }\end{array}$ & $\begin{array}{l}\text { Measured } \\
\text { Distance }\end{array}$ & Strengths & Weaknesses & Application & Opportunities & Threats & $\begin{array}{l}\text { Perceived } \\
\text { Energy }\end{array}$ & $\begin{array}{c}\text { Recognizing } \\
\text { Vehicle }\end{array}$ \\
\hline $\begin{array}{l}\text { LASER } \\
\text { based } \\
\text { sensors }\end{array}$ & $\begin{array}{l}\text { Derivative } \\
\text { of range }\end{array}$ & $\begin{array}{l}\text { Time of } \\
\text { flight }\end{array}$ & $\begin{array}{l}\text { Reliable for } \\
\text { automatic car } \\
\text { parking and } \\
\text { collision } \\
\text { mitigation }\end{array}$ & $\begin{array}{l}\text { Vulnerable to } \\
\text { dirty lenses and } \\
\text { reflecting target } \\
\text { reduced. }\end{array}$ & $\begin{array}{l}\text { Collision } \\
\text { warning, } \\
\text { assistant } \\
\text { automatic } \\
\text { parking }\end{array}$ & $\begin{array}{l}\text { Gives } \\
\text { warning for } \\
\text { excessive } \\
\text { load or } \\
\text { strain. }\end{array}$ & $\begin{array}{l}\text { Failure due to } \\
\text { inclement } \\
\text { weather }\end{array}$ & $\begin{array}{c}\text { 600-1000 } \\
\text { emitted laser } \\
\text { waves } \\
\text { (Nanome- } \\
\text { ters) }\end{array}$ & $\begin{array}{l}\text { Resolved } \\
\text { via spatial } \\
\text { segmenta- } \\
\text { tion and } \\
\text { motion }\end{array}$ \\
\hline $\begin{array}{l}\text { RADAR } \\
\text { based } \\
\text { sensors }\end{array}$ & Frequency & $\begin{array}{l}\text { Time of } \\
\text { flight }\end{array}$ & $\begin{array}{l}\text { Suitable for } \\
\text { collision } \\
\text { mitigation and } \\
\text { adaptive }\end{array}$ & $\begin{array}{l}\text { Vulnerable and } \\
\text { sometimes fails } \\
\text { for extreme } \\
\text { weather } \\
\text { condition }\end{array}$ & $\begin{array}{l}\text { Collision } \\
\text { warning, } \\
\text { assistant } \\
\text { automatic } \\
\text { parking }\end{array}$ & $\begin{array}{c}\text { Better } \\
\text { accuracy } \\
\text { and required } \\
\text { no attention }\end{array}$ & $\begin{array}{l}\text { Inappropriate } \\
\text { and difficult to } \\
\text { implementa- } \\
\text { tion by } \\
\text { non- } \\
\text { professional }\end{array}$ & $\begin{array}{c}\text { Emitted } \\
\text { radio single } \\
\text { wave } \\
\text { (Millimeter) }\end{array}$ & $\begin{array}{c}\text { Resolved } \\
\text { via tracking }\end{array}$ \\
\hline $\begin{array}{l}\text { Vision } \\
\text { based } \\
\text { sensors }\end{array}$ & $\begin{array}{l}\text { Derivative } \\
\text { of range }\end{array}$ & $\begin{array}{c}\text { Model } \\
\text { parameter }\end{array}$ & $\begin{array}{c}\text { Readily } \\
\text { available and } \\
\text { affordable in } \\
\text { the automobile } \\
\text { sector }\end{array}$ & $\begin{array}{l}\text { Vulnerable to } \\
\text { extreme weather } \\
\text { conditions and } \\
\text { sometimes fails } \\
\text { to work in the } \\
\text { night time. }\end{array}$ & $\begin{array}{l}\text { Collision } \\
\text { warning, } \\
\text { assistant } \\
\text { automatic } \\
\text { parking. }\end{array}$ & $\begin{array}{l}\text { Low cost, } \\
\text { passive } \\
\text { non-invasive } \\
\text { sensors and } \\
\text { low } \\
\text { operating } \\
\text { power. }\end{array}$ & $\begin{array}{l}\text { Less effective } \\
\text { for bad } \\
\text { weather, for } \\
\text { complex } \\
\text { illumination } \\
\text { and shadow }\end{array}$ & $\begin{array}{c}\text { Ambient } \\
\text { visible light }\end{array}$ & $\begin{array}{c}\text { Resolved } \\
\text { via motion } \\
\text { and } \\
\text { appearance }\end{array}$ \\
\hline
\end{tabular}

\subsubsection{LASER Based Sensors}

Laser scanner and Light detection and ranging (LIDAR) is the common laser-based sensors. In this technology, the transmitter and receiver are placed, and the impulse light of electromagnetic waves are recorded through it. Infrared near about $(800-950 \mathrm{~nm})$ and ultraviolet above $(1500 \mathrm{~nm})$ wavelength of the electromagnetic spectrum are used [19]. By estimating the time of flight, the distance between the transmitter and the receiver is calculated. It may not be possible to derive the direct relative velocity of the moving object, so it is obtained by taking the derivative of ranges with respect to time. These types of sensors are used for multiple target tracking. The drawbacks of these sensors are vulnerability to dirty lenses and the inadequacy of the reflecting target. Besides, for weather conditions, these sensors may be too sensitive. These types of sensors are reliable for automatic car parking and collision mitigation $[19,20]$.

\subsubsection{RADAR Based Sensors}

RADAR sensors can detect the images in haze, dust, rain, and snow up to $200 \mathrm{~m}$ ahead. Through the radar detection and ranging process, these sensors emit strong radio waves through the transmitter and receive them back through the receiver, similar to laser-based sensors. The distance between sensors and objects is calculated by the time of flight. Another advantage is that frequency between emitted and Doppler echo can be calculated, which provides the object's velocity. To map movements of aircraft, these kinds of sensors are often used in aviation and defence manufacturing sectors. In the automobile sector, two types of sensors are used: long-range sensors, which range between $77-81 \mathrm{GHz}$ spectrum and short-range sensors that range between $21.65-26.65 \mathrm{GHz}$. In extreme weather conditions, these sensors are very vulnerable and sometimes fail to work. These kinds of sensors are used for collision mitigation and adaptive cruise control [19,20].

\subsubsection{Vision-Based Sensors}

These types of sensors come under the passive sensors category, which means they do not emit any waves. To assess the presence, orientation and accuracy of the surrounding 
objects, vision sensors use images. Vision sensors use a mixture of image acquisition and image processing, and multi-point inspection is carried out using a single sensor. Two types of sensors are used in a vision-based system, the first is a monocular camera, and the second is a stereo vision camera. These sensors do not directly derive the range and velocity of the objects, and as such, a sophisticated signal procedure is used to derive these parameters. These sensors are readily available and affordable in the automobile sector. For traffic signal analysis and lane change assistance, these kinds of sensors are applicable. The main drawback is vulnerabilty to extreme weather conditions and sometimes failing to work at nighttime $[19,20]$.

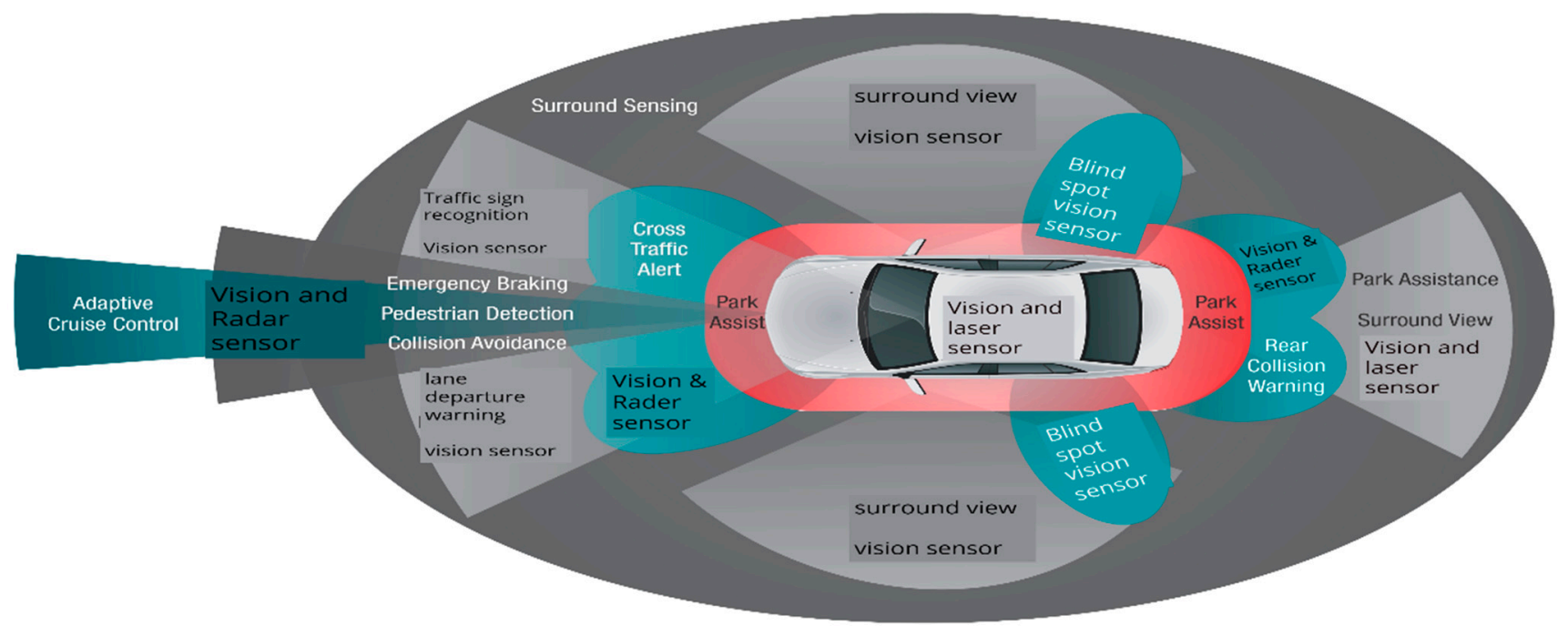

Figure 2. Sensors fusion to guide autonomous vehicle, adapted and reprinted from ref. [21].

\subsection{Lane Detection and Tracking Algorithms}

In this section, we have conducted a comparison and analysis of algorithms in three different categories according to approaches used: features-based approach, model-based and learning-based approach.

The feature-based approach uses edges and local visual characteristics of interest, such as gradient, colour, brightness, texture, orientation, and variations, which are relatively insensitive to road shapes but sensitive to illumination effects. The model-based approaches apply global road models to fit low levels of features that are more robust against illumination effects, but they are sensitive to road shapes $[13,14]$. The geometrics parameters are used in the model-based approach for lane detection [16-18]. The learning-based approach consists of two stages: training and classification. The training process uses previously known errors and system properties to construct a model, e.g., program variables. In addition, the classification phase applies the training model to the user set of properties and outputs that are more likely to be correlated with the error ordered by their probability of fault discloser [19]. In the following sections, we describe the three approaches used in the literature in detail. It is then followed up by summary tables (Tables 2-5) that present the key features of these algorithms and strengths, weaknesses, and future prospects.

\subsubsection{Features-Based Approach (Image and Sensor-Based Lane Detection and Tracking)}

Image and sensor-based lane detection and tracking decision-making processes are dependent on the sensors attached to the vehicle and the camera output. In this approach, the image frames are pre-processed, and a lane detection algorithm is applied to determine lane tracking. The sensor values are used to further decide on the path to be followed by the lane markings [22,23].

Kuo et al. [24] implemented a vision-based lane-keeping system. The proposed system obtains the vehicle position following the lane and controls the vehicle to be in 
the desired path. The steps involved in the lane-keeping system are inverse perspective mapping, detection of lane scope features and reconstruction of the lane markings. The main drawback of the system is that the performance is reduced when the vehicle is driving in a tunnel.

Kang et al. [25] proposed a kinematic-based fault-tolerant mechanism to detect the lane even if the camera cannot provide the road image due to malfunction or environmental constraints. In the absence of camera input, the lane is predicted using the kinematic model by taking the parameters such as the length and speed of the vehicle. The camera input is given as a clothoid cubic polynomial curve road model. In the absence of camera input, the lane coefficients of the clothoid model will be available. A lane restoration scheme is used to overcome this loss based on a multi-rate state estimator obtained from the kinematic lateral motion model in the clothoid function. The predicted lane is based on the past curvature rate and road curvature. The results show that the proposed method can maintain the lane for $3 \mathrm{~s}$ without camera input. The developed algorithm was simulated using CARSIM and Simulink. It has been tested in a test vehicle equipped with an Auto Box from dSPACE in Tucson from HYUNDAI Motors.

Borkar et al. [26] proposed a lane detection and tracking method using inverse projective mapping (IPM) to create a bird's-eye view of the road; a Hough transform for detecting candidate lane and Kalman filter track the lane. The road image is converted to grayscale form followed by temporal blurring. The application of IPM makes the image provide a bird's eye view. The lanes are detected by identifying the pair of parallel lines which are separated by a distance. The IPM images are converted to binary, and a Hough transform is performed on the binary image and then divided into two halves. To determine the center of the line, the one-dimensional matched filter is applied to each sample. The pixel with a large correlation that exceeds the threshold is selected as the center of the lane. The Kalman filter is used to track the lane, which takes the lane orientation and difference between the current and previous frames. A firewire camera is used to capture the image of the road. The performance of the proposed algorithm provides better accuracy under the isolated highway and metro highway, and the accuracy is in the range of $86 \%$ on city roads. The improved performance is due to the usage of the Kalman filter to track the lane.

Sun et al. [27] proposed a lane detection mechanism considering multiple frames in contrast with the single frame along with the inertial work classifier. The initially assigned probability value changes due to error and vehicle movement. Kalman filter is applied to smooth the line segments in Hough space. The inertial measurement unit (IMU) values are used to align the previous line segments in the Hough space. The lane detection is determined by considering the line segments with a high probability value. The analysis of the method using the Caltech dataset provides accuracy in the range of $95 \%$ to $97 \%$. The lane detection under different environmental conditions such as sunlight, rain and with high values of sunlight and rainfall shows the performance in the range of $72 \%$ to $87 \%$. The Hough transform is employed to extract the line segment from lane markings stored in the Hough space. The Hough space is used to store the line segments with an associated probability value. The truthiness of the line segments is determined using Convolutional Neural Net. The system is implemented using NVIDIA GTX1050ti GPU, OV10650 camera, and the IMU is Epson G320.

Lu et al. [28] proposed a lane detection algorithm for urban traffic scenarios in which the road is well-constructed, flat and of equal width. The road model is constructed using feature line pairs (FLP), the FLP is detected using Kalman filter and a regression diagnostic technique to determine the road model using FLP. The result shows that the time taken to detect the road parameters is $11 \mathrm{~ms}$. The proposed method is implemented using $\mathrm{C}++$ on a 1.33 GHz AMD processor-based personal computer with a single camera and a Matrox Meteor RGB/PPB digitizer and implemented in THMR-V (Tsinghua Mobile Robot V).

Zhang and Shi [29] proposed a lane detection method for detecting the lanes at night. The sober and canny operator detects the edges of the lanes. Gradients acquiring a certain threshold are labelled as edge points. The histogram with the higher brightness is named 
as lane boundary, and the low valued histogram is named a road. The accuracy of the proposed method is high even in the presence of noises from car head and rear lights and road contour signs.

Borkar et al. [30] proposed a layered approach to detect the lane at night. The region of interest is specified in the captured image of the road. The image is converted to greyscale for further processing. Temporal burring is applied to obtain the continuous lanes of the long line. Depending on the characteristics of the neighboring pixels, an adaptive controller is used to determine the object. The images are converted to the left and right halves, and each half Hough transform is performed to determine the straight lines. The final process deals with the fitting of all the straight lines. Firewire S400 (400 Mbps) color camera in VGA resolution $(640 \times 480)$ at $30 \mathrm{fps}$ is used to capture the video and fed to MATLAB, and lanes are detected in an offline manner. The performance of the proposed method is good in isolated highways and in metro highway scenarios. With moderate traffic, the accuracy of detecting the lanes is reduced to 80 percent.

Priyadarshini et al. [31] proposed a lane detection system that detects the lane during the daytime. The captured video is converted to a grayscale image. A Gaussian filter is applied to remove the noise. The Canny edge detection algorithm is used to detect the edges. To identify the length of the lane, a Hough transform is applied. The proposed method is simulated using a raspberry pi-based robot with a camera and ultrasonic sensors to determine the distance between neighbouring vehicles.

The survey by Hong et al. [32] discussed video processing techniques to determine the lanes illumination change on the region of interest for straight-line roads. The survey highlights the methodologies involved, such as choosing the proper color space and determination of the region of interest. Once the intended image is captured, a color segmentation operation is performed using region splitting and clustering schemes. This is followed by applying the merging algorithm to suppress the noise in the image.

A color-based lane detection and a representative line extraction algorithm are proposed by Park et al. [33]. The captured image in RGB format is converted to gray code followed by binary image conversion. The purpose of binary image conversion is to remove the shadows in the captured image. The lanes in the image are detected using the canny algorithm by the feature named color. The direction and intensity are determined by removing the noise using the gaussian filter. The images are smoothened by applying a median filter. The lanes in the image are considered as the region of interest, and Hough transform is applied to confirm the accuracy of the lanes in the region of interest. The experiment is performed during the daytime. The results show that the lane detection rate is more than $93 \%$.

El Hajjouji et al. [34] proposed a hardware architecture for detecting straight lane lines using Hough transform. The CORDIC (Coordinate Rotation Digital Computer) algorithm calculates the gradient and phase from the captured image. The output of CORDIC block is the norm and angle of the x-axis of the image. The norm and angles are compared with the threshold obtained from the region of interest. The Hough transform is applied to the outcome of the comparator module, and the relation between the Hough space and the angle is determined. The noises are removed by the Hough transform voting procedure. Finally, the output is obtained as the slope of the straight line. The algorithm is implemented in the Virtex-5 ML505 platform. The algorithm was tested on a variety of images with varying illumination and different road conditions, such as urban streets, highways, occlusion, poor line paintings, day and night and scenarios. The algorithm provides a detection rate of $92 \%$.

Samadzadegan et al. [35] proposed a lane detection methodology in a circular arc or parabolic based geometric method. The RGB colour is converted to an intensity image that contains a specific range of values. A three-layer pyramid image is constructed using bi-cubic interpolation method. Among the three layers of region of interest, the first layer pixels undergo randomized Hough transformation to determine the curvature and orientation features followed by a Genetic Algorithm Optimisation. The process is repeated 
to the remaining two layers. The outcome obtained in the lower layers are the features of the lane and used to determine the lanes in the region of interest. The result shows that there is a performance drop in lane detection when entering the tunnel region and occlusion in lane markings due to the shadow of another vehicle.

Cheng et al. [36] proposed a hierarchical lane detection system to detect the lanes on structured and unstructured roads. The system classifies the environment into structured and unstructured based on the feature extraction, which depends on the color of the lane marking. The connected component labelling method is applied to determine the feature objects. During the training, phase supervised learning is performed and manually classified the objects as left lane, right lane and no lane markings. The image is classified as structured and unstructured based on the vote value associated with the weights. The lanes for structured roads are detected by eliminating the moving vehicle on the lane image followed by lane recognition by considering the angle of inclination and starting points of the lane markings. The lane coherence verification module compares the lane width of the current frame with the previous frame to determine the lanes. For unstructured roads, the following steps are performed: mean shift segmentation, which deals with the determination of road surface by comparing with the surroundings to determine the variation in colors and texture. The region merging and boundary smoothing module deals with pruning unnecessary boundary lines and neglecting the region which is smaller than the threshold. The boundary is selected based on the posterior probability of each set of candidates. The simulation results show that around $0.11 \mathrm{~s}$ is needed to identify structured or unstructured roads. The system achieves an accuracy of $97 \%$ in lane detection.

Han et al. [37] proposed a LIDAR sensor-based road boundary detection and tracking for both structured and unstructured roads. The LIDAR is used to obtain the polar coordinates. The line segments are obtained from the height and pitch of LIDAR. Information such as roadside, curbs, sidewalks and buildings are obtained from the line segments. The road slope and width are obtained by merging two-line segments. The road is tracked using the nearest neighbor filter to estimate the state of the target. The algorithm is tested in a real vehicle equipped with LIDAR, GPS and IMU. The road boundary detection accuracy is $95 \%$ for structured and $92 \%$ for unstructured roads.

Le et al. [38] proposed a method to detect pedestrian lanes under different illumination conditions with no lane markings. The first stage of the proposed system is the vanishing point estimation which works based on votes of local orientations from colored edge pixels. The local orientation of pixels is determined as the vanishing point. The next stage is the determination of the sample region of the lane from the vanishing point. To achieve higher robustness towards different illuminations, invariant space is used. Finally, the lanes are detected using the appearance and shape information from the input image. A Greedy algorithm is applied, which helps to determine the connectivity between the lanes in each iteration of the input image. The proposed model is tested on the input image of both indoor and outdoor environments. The results show that the lane detection accuracy is $95 \%$.

Wang et al. [39] proposed a lane detection system for straight and curve road scenarios. The captured image determines the region of interest, set as $60 \mathrm{~m}$ which falls in the near field region. The region of interest is divided into the straight region and the curve region. The near field region is approximated as the straight line, and the far-field region is approximated as the curve. An improved Hough transform is applied to detect the straight line. The curve is determined in the far-field region using the least-squares curve fitting method. The WAT902H2 camera model is used to capture the image of the road. The results show that the time taken to determine the straight and curve lane is $60-80 \mathrm{~ms}$ compared to 70-100 ms in the existing works and the accuracy is around $92-93 \%$. The error rate in bending to the left or right direction is from -0.85 to $5.20 \%$ for different angles.

Yeniaydin [40] proposed a lane detection algorithm based on camera and 2D LIDAR input data. The camera obtains the bird's eye view of the road, and the LIDAR detects the location of objects. The proposed method consists of the steps mentioned below: 
- Obtain the camera and 2D LIDAR data.

- Perform segmentation operation of the LIDAR data to determine groups of objects. It is done based on the distance among different points.

- Map the group or objects to the camera data.

- Turn the pixels of groups or objects into camera data. It is done by the formation of the region of interest based on a rectangular region. Straight lines are drawn from the location of the camera to the corner of the region of interest. The convex polygon algorithm determines the background and occluded region of the image.

- Apply lane detection to the binary image to detect the lanes. The proposed approach shows better accuracy compared with the traditional methods for a distance less than $9 \mathrm{~m}$.

Kemsaram et al. [41] proposed a deep learning-based approach for detecting lanes, objects and free space. The Nvidia tool comes with SDK (software development kit) with inbuilt options for object detection, lane detection and free space detection. The object detection module loads the image and applies transformations to the image to detect different objects. The lane detection framework uses the lane Net pipeline, which uses the images. The lanes are assigned with numbers from left to right. For each frame, the lane detection framework determines the lane markings. The lane detection function creates the pixel coordinates $(x, y)$ for each lane marking. The free space module can identify the free space on the surface and in front of the vehicle. The proposed method is implanted in $\mathrm{C}++$ and runs real-time on Nvidia Drive PX 2 platform. The time taken to determine the lane falls under 6 to $9 \mathrm{~ms}$.

\subsubsection{Model-Based Approach (Robust Lane Detection and Tracking)}

Lee and Moon [42] proposed a robust lane detection and tracking system. This system's main aim is to detect the lane and track by considering different environmental conditions such as clear sky, rainy, and snowy during morning and night. The proposed system consists of three phases, namely initialization, lane detection, and lane tracking. In the initialization phase, the road region is captured and pre-processed to a low-resolution image. The edges are extracted, and the image is split into the left half and right half region. An intersection point is made from both regions, and intersection points are mostly found near the vanishing point. Once the vanishing points become greater than the threshold, the region above and below the vanishing points is removed. In the lane marking detection phase, the lane marking is determined in the rectangular region of interest. The image is converted into greyscale by using edge line detection, and a line segment is detected. The hierarchical agglomerative clustering method is used for a color image. The line segment is determined from surrounding vehicles, shadows, trees, and buildings by using its frequency in the region of interest. Other disturbances are not continuous compared to the real lane marking, and they can be determined by comparing them with the consecutive frames. In the lane tracking phase, lane tracking is achieved from the modified region of interest. Multiple pairs of lanes with the same weight are considered, and the smallest are chosen. Some lanes, which are not detected, are predicted by using the Kalman filter. This system is tested using $\mathrm{C}++$ and open CV library with Ubuntu14. There is scope for improvement of the algorithm during the night scenario.

Son et al. [43] proposed a robust multi-lane detection and tracking algorithm to determine the lane accurately under different road conditions such as poor road marking, obstacles and guardrails. An adaptive threshold is used to extract strong lane features from images that are not clear. The next step is to extract the erroneous lane features and apply the random sample consensus algorithm to prevent false lane detection. The selected lanes are verified using the lane classification algorithm. The advantage of this approach is that no prior knowledge of the lane geometry is required. The scope for improvement is the detection of the false lane under the different urban driving scenarios.

Li et al. [44] proposed a real-time robust lane detection method consisting of three methods: lane marking extraction, geometric model estimation, and tracking key points of the geometric 
model. In the lane extraction process, lane width is chosen according to the standards followed in the country. The gradient of each pixel is used to estimate the edge points of lane marking.

Son et al. [45] proposed a method that uses the illumination property of lanes under different conditions, as it is a challenge to detect the lane and keep the lane on track under different conditions. The methodology involves the determination of the vanishing point and in which the bottom half of the image is analyzed using a canny edge detector and Hough transform. The second step involves the determination of white lanes or yellow lanes based on the illumination property. The white and yellow lanes are used to obtain the binary image of the lane. The lanes are labelled, and the angles are made to intercept the $y$-axis. If there is a match, they are grouped to determine long lanes.

Chae et al. [46] proposed an autonomous lane changing system consisting of three modules: perception, motion planning, and control. The surrounding vehicles are detected using LIDAR sensor input. In motion planning, the vehicle determines the mode such as lane-keeping or lane change, followed by the desired motion that is planned considering the safety of surrounding vehicles. A linear quadratic regulator (LQR) based model predictive control is used for longitudinal acceleration and deciding the steering angle. The stochastic model predictive control is used for lateral acceleration.

Chen et al. [47] proposed a deep convolutional neural network to detect the lane markings. The modules involved in the lane detection process are lane marking generation, grouping, and lane model fitting. The lane grouping process involves forming a cluster comprising neighbouring pixels represented as a single label that belongs to the same lane and connecting the labels called super marking. The next step of lane model fitting uses 3rd order polynomial to represent straight and curved lanes. The simulation is done on the CAMVID dataset. The setup requires high-end systems to do the training. The algorithm is evaluated for a minimal real-time situation. The authors proposed a Global Navigation Satellite System (GNSS) based lane-keeping assistance system, which calculates the target steering angle using a model predictive controller. The advantage of the approach is that it is estimated from GNSS when the lane is not visible due to environmental constraints. The steering angle and acceleration are modelled using the first-order lag system. The model predictive control is used to control the lateral movement of the vehicle. The proposed system was simulated, and prototype testing was conducted in a real vehicle, OUTLANDER PHEV (Mitsubishi Motors Corporation). The results show that the lane is followed with a minimal lateral error of about $0.19 \mathrm{~m}$. The drawback of the approach is that the time delay of GNSS has an impact on the oscillation in the steering. Hence, the GNSS time delay should be kept minimal compared to the steering time delay.

Lu et al. [48] proposed a lane detection approach using Gaussian distribution random sample consensus (G-RANSAC). The process involves converting a bird's eye view image to look at all the lane characteristics. The next step is using a ride detector to extract the features of lane points and remove noise points using an adaptable neutral network. The ridge features are extracted from the gray images, which provide better results during the presence of vehicle shadow and minimal illumination on the environment. Finally, the lanes are detected using the RANSAC approach. The RANSAC algorithm considers the confidence level of ridge points in determining the lanes from noise. The proposed algorithm is tested under four different illumination conditions: normal illumination and good pavement, intense illumination and shadow interruption, normal illumination and sign-on-the-ground interruption and poor illumination and vehicle interference. The algorithm achieved $99.02 \%, 96.92 \%, 96.65 \%$ and $91.61 \%$ true-positive rates respectively.

\subsubsection{Learning-Based Approach (Predictive Controller Lane Detection and Tracking)}

Bian et al. [49] implemented a lane-keeping assistance system (LKAS) with two switchable assistance modes: lane departure prevention and lane-keeping co-pilot modes. The LKAS is designed to achieve better reliability. The two switchable assistance modes consist of a conventional Lane Departure Prevention (LDP) mode and a lane-keeping Co-pilot (LK Co-Pilot) mode. The LDP mode is activated if a lane departure is detected. A lateral offset is used as a 
lane-departure metric to determine whether to trigger the LDP or not. The LK Co-pilot mode is activated if the driver does not intend to change the lane; this mode helps the driver follow the expected trajectory based on the driver's dynamic steering input. Care should be taken to set the threshold accurately and adequately; otherwise false lane detection would be increased.

Wang et al. [50] proposed a lane-changing strategy for autonomous vehicles using deep reinforcement learning. The parameters which are considered for the reward are delay and traffic on the road. The decision to switch lanes depends on improving the reward by interacting with the environment. The proposed approach is tested under accident and non-accident scenarios. The advantage of this approach is collaborative decision making in lane changing. Fixed rules may not be suitable for heterogeneous environmental or traffic scenarios.

Wang et al. [51] proposed a reinforcement learning-based lane change controller for a lane change. Two types of lane change controllers are adopted, namely longitudinal and lateral control. A car-following model, namely the intelligent driver model, is chosen for the longitudinal controller. The lateral controller is implemented by reinforcement learning. The reward function is based on yaw rate, acceleration, and time to change the lane. To overcome the static rules, a Q-function approximator is proposed to achieve continuous action space. The proposed system is tested in a custom-made simulation environment. Extensive simulation is expected to test the efficiency of the approximator function under different real-time scenarios.

Suh et al. [52] implemented a real-time probabilistic and deterministic lane changing motion prediction system which works under complex driving scenarios. They designed and tested the proposed system on both a simulation and real-time basis. A hyperbolic tangent path is chosen for the lane-change maneuver. The lane changing process is initiated if the clearance distance is greater than the minimum safe distance and the position of other vehicles. A safe driving envelope constraint is maintained to check the availability of nearby vehicles in different directions. A stochastic model predictive controller is used to calculate the steering angle and acceleration from the disturbances. The disturbance values are obtained from experimental data. The usage of advanced machine learning algorithms could improve the currently developed system's reliability and performance.

Gopalan et al. [53] proposed a lane detection system to detect the lane accurately under different conditions such as lack of prior knowledge of the road geometry, lane appearance variation due to change in environmental condition, and independent of vehicle speed. The modules of the proposed system are lane detection and tracking. The basic approach used for lane detection is to classify the lane markings from the non-lane markings from the labelled training sample. A pixel hierarchy feature descriptor method is proposed to identify the correlation between the lane and its surroundings. A machine learning-based boosting algorithm is used to identify the most relevant features. The advantage of the boosting algorithm is the adaptive way of increasing or decreasing the weightage of the samples. The lane tracking process is performed during the non-availability of knowledge about the motion pattern of lane markings. Lane tracking is achieved by using particle filters to track each of the lane markings and understand the cause for the variation. The variance is calculated for different parameters such as the initial position of the lane, motion of the vehicle, change in road geometry, traffic pattern. The variance associated with the above parameters is used to track the lane under different environmental conditions. The learning-based proposed system provides better performance under different scenarios. The point to consider is that the assumption made is the flat nature of the road. The flat road image was chosen to avoid the sudden appearance and disappearance of the lane. The proposed system is implemented at the simulation level.

To summarize the progress made in lane detection and tracking as discussed in this section, Table 2 has been presented that shows the key steps involved in the three approaches for lane detection and tracking, along with remarks on their general characteristics. It is then followed with Tables 3-5 that presents the summary of data used, strengths, drawbacks, key findings and future prospects of the key studies that have adopted the three approaches in the literature. 
Table 2. A summary of methods used for lane detection and tracking with general remarks.

\begin{tabular}{|c|c|c|c|c|c|}
\hline Methods & Steps & Tool Used & Data Used & Methods Classification & Remarks \\
\hline $\begin{array}{l}\text { Image and sensor-based lane } \\
\text { detection and tracking }\end{array}$ & 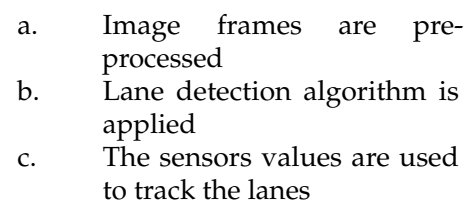 & $\begin{array}{l}\text { Camera } \\
\text { Sensors }\end{array}$ & sensors values & Feature-based approach & $\begin{array}{l}\text { Frequent calibration is required for } \\
\text { accurate decision making in a } \\
\text { complex environment }\end{array}$ \\
\hline $\begin{array}{l}\text { Predictive controller for lane } \\
\text { detection and controller }\end{array}$ & $\begin{array}{l}\text { Machine learning technique (e.g., } \\
\text { neural networks,) }\end{array}$ & $\begin{array}{ll}\text { a. } & \begin{array}{l}\text { Model predictive con- } \\
\text { troller }\end{array} \\
\text { b. } & \text { Reinforcement learning al- } \\
\text { gorithms }\end{array}$ & $\begin{array}{l}\text { data obtained from the } \\
\text { controller }\end{array}$ & Learning-based approach & $\begin{array}{l}\text { Reinforcement learning with model } \\
\text { predictive controller could be a } \\
\text { better choice to avoid false lane } \\
\text { detection. }\end{array}$ \\
\hline $\begin{array}{l}\text { Robust lane detection and } \\
\text { tracking }\end{array}$ & $\begin{array}{l}\text { a. Capture an image through } \\
\text { camera } \\
\text { b. Use Edge detector to data for } \\
\text { extract the features of the im- } \\
\text { age } \\
\text { c. Determination of vanishing } \\
\text { point }\end{array}$ & $\begin{array}{l}\text { Based on robust lane detection } \\
\text { model algorithms }\end{array}$ & Real-time & Model-based approach & $\begin{array}{l}\text { Provides better result in different } \\
\text { environmental conditions. Camera } \\
\text { quality plays important role in } \\
\text { determining lanes marking }\end{array}$ \\
\hline
\end{tabular}

Table 3. A comprehensive summary of lane detection and tracking algorithm.

\begin{tabular}{|c|c|c|c|c|c|c|c|c|c|c|}
\hline \multirow[b]{2}{*}{ Sources } & \multicolumn{2}{|c|}{ Data } & \multirow[b]{2}{*}{ Method Used } & \multirow[b]{2}{*}{ Advantages } & \multirow[b]{2}{*}{ Drawbacks } & \multirow[b]{2}{*}{ Results } & \multirow[b]{2}{*}{ Tool Used } & \multirow[b]{2}{*}{ Future Prospects } & \multirow[b]{2}{*}{ Data } & \multirow[b]{2}{*}{ Reason for Drawbacks } \\
\hline & 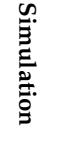 & $\underset{0}{\pi}$ & & & & & & & & \\
\hline [24] & & $\mathrm{Y}$ & $\begin{array}{l}\text { Inverse perspective } \\
\text { mapping method is } \\
\text { applied to convert the } \\
\text { image to bird's eye view. }\end{array}$ & $\begin{array}{l}\text { Minimal error and quick } \\
\text { detection of lane. }\end{array}$ & $\begin{array}{l}\text { The algorithm performance } \\
\text { drops when driving in } \\
\text { tunnel due to the } \\
\text { fluctuation in the lighting } \\
\text { conditions. }\end{array}$ & $\begin{array}{l}\text { The lane detection error is } \\
5 \% \text {. The cross-track error is } \\
25 \% \text { and lane detection time } \\
\text { is } 11 \mathrm{~ms} \text {. }\end{array}$ & $\begin{array}{l}\text { Fisheye dashcam, } \\
\text { inertial } \\
\text { measurement unit } \\
\text { and ARM } \\
\text { processor-based } \\
\text { computer. }\end{array}$ & $\begin{array}{l}\text { Enhancing the } \\
\text { algorithm suitable } \\
\text { for complex road } \\
\text { scenario and with } \\
\text { less light } \\
\text { conditions. }\end{array}$ & $\begin{array}{c}\text { Data obtained } \\
\text { by using a } \\
\text { model car } \\
\text { running at a } \\
\text { speed of } 100 \\
\mathrm{~m} / \mathrm{s} .\end{array}$ & $\begin{array}{l}\text { Performance drop in } \\
\text { determining the lane, if the } \\
\text { vehicle is driving in a } \\
\text { tunnel and the road } \\
\text { conditions where there is no } \\
\text { proper lighting. } \\
\text { The complex environment } \\
\text { creates unnecessary tilt } \\
\text { causing some inaccuracy in } \\
\text { lane detection. }\end{array}$ \\
\hline
\end{tabular}


Table 3. Cont.

\begin{tabular}{|c|c|c|c|c|c|c|c|c|c|c|}
\hline \multirow[b]{2}{*}{ Sources } & \multicolumn{2}{|c|}{ Data } & \multirow[b]{2}{*}{ Method Used } & \multirow[b]{2}{*}{ Advantages } & \multirow[b]{2}{*}{ Drawbacks } & \multirow[b]{2}{*}{ Results } & \multirow[b]{2}{*}{ Tool Used } & \multirow[b]{2}{*}{ Future Prospects } & \multirow[b]{2}{*}{ Data } & \multirow[b]{2}{*}{ Reason for Drawbacks } \\
\hline & 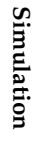 & 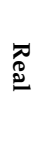 & & & & & & & & \\
\hline [25] & & $\mathrm{Y}$ & $\begin{array}{l}\text { Kinematic motion model } \\
\text { to determine the lane } \\
\text { with minimal parameters } \\
\text { of the vehicle. }\end{array}$ & $\begin{array}{l}\text { No need for } \\
\text { parameterization of the } \\
\text { vehicle with variables like } \\
\text { cornering stiffness and } \\
\text { inertia. Prediction of lane } \\
\text { even in absence of camera } \\
\text { input for around } 3 \mathrm{~s} \text {. }\end{array}$ & $\begin{array}{l}\text { The algorithm suitable for } \\
\text { different environment } \\
\text { situation not been } \\
\text { considered }\end{array}$ & $\begin{array}{l}\text { Lateral error of } 0.15 \mathrm{~m} \text { in the } \\
\text { absence of camera image. }\end{array}$ & $\begin{array}{l}\text { Mobileye camera, } \\
\text { carsim and MAT- } \\
\text { LAB/Simulink, } \\
\text { Auto box from } \\
\text { dSPACE. }\end{array}$ & $\begin{array}{l}\text { Trying the fault } \\
\text { tolerant model in } \\
\text { real vehicle. }\end{array}$ & Test vehicle & - \\
\hline [26] & $\mathrm{Y}$ & & $\begin{array}{l}\text { Usage of inverse } \\
\text { mapping for the creation } \\
\text { of bird's eye view of the } \\
\text { environment. }\end{array}$ & $\begin{array}{l}\text { Improved accuracy of lane } \\
\text { detection in the range of } \\
86 \% \text { to } 96 \% \text { for different } \\
\text { road types. }\end{array}$ & $\begin{array}{l}\text { Performance under } \\
\text { different vehicle speed and } \\
\text { inclement weather } \\
\text { conditions not considered. }\end{array}$ & $\begin{array}{c}\text { The algorithm requires } 0.8 \mathrm{~s} \\
\text { to process frame. Higher } \\
\text { accuracy when more than } \\
59 \% \text { of lane markers are } \\
\text { visible. }\end{array}$ & $\begin{array}{l}\text { Firewire color } \\
\text { camera, MATLAB }\end{array}$ & $\begin{array}{l}\text { Real-time } \\
\text { implementation of } \\
\text { the work }\end{array}$ & $\begin{array}{l}\text { Highway and } \\
\text { streets and } \\
\text { around Atlanta }\end{array}$ & - \\
\hline [27] & $\mathrm{Y}$ & $\mathrm{Y}$ & $\begin{array}{l}\text { Hough transform to } \\
\text { extract the line segments, } \\
\text { usage of a convolutional } \\
\text { neural network-based } \\
\text { classifier to determine the } \\
\text { confidence of line } \\
\text { segment. }\end{array}$ & Tolerant to noise & $\begin{array}{l}\text { In the custom dataset, the } \\
\text { performance drops } \\
\text { compared to Caltech } \\
\text { dataset. }\end{array}$ & $\begin{array}{l}\text { For urban scenario, the } \\
\text { proposed algorithm } \\
\text { provides accuracy greater } \\
\text { than } 95 \% \text {. The accuracy } \\
\text { obtained in lane detection } \\
\text { in the custom setup is } 72 \% \\
\text { to } 86 \% \text {. }\end{array}$ & $\begin{array}{c}\text { OV10650 camera } \\
\text { and I MU is Epson } \\
\text { G320. }\end{array}$ & $\begin{array}{l}\text { Performance } \\
\text { improvement is } \\
\text { future } \\
\text { consideration. }\end{array}$ & $\begin{array}{l}\text { Caltech dataset } \\
\text { and custom } \\
\text { dataset. }\end{array}$ & $\begin{array}{l}\text { The device specification } \\
\text { and calibration, it plays } \\
\text { important role in capturing } \\
\text { the lane. }\end{array}$ \\
\hline [28] & & $\mathrm{Y}$ & $\begin{array}{l}\text { Feature-line-pairs (FLP) } \\
\text { along with Kalman filter } \\
\text { for road detection. }\end{array}$ & $\begin{array}{l}\text { Faster detection of lanes, } \\
\text { suitable for real-time } \\
\text { environment. }\end{array}$ & $\begin{array}{l}\text { Testing the algorithm } \\
\text { suitability under different } \\
\text { environmental conditions } \\
\text { could be done. }\end{array}$ & $\begin{array}{l}\text { Around } 4 \mathrm{~ms} \text { to detect the } \\
\text { edge pixels, } 80 \mathrm{~ms} \text { to detect } \\
\text { all the FLPs, } 1 \mathrm{~ms} \text { to } \\
\text { determine the extract road } \\
\text { model with Kalman filter } \\
\text { tracking. }\end{array}$ & $\begin{array}{l}\mathrm{C}++ \text {; camera and a } \\
\text { matrox meteor } \\
\text { RGB / PPB } \\
\text { digitizer. }\end{array}$ & $\begin{array}{l}\text { Robust tracking } \\
\text { and improve the } \\
\text { performance in } \\
\text { urban dense } \\
\text { traffic. }\end{array}$ & Test robot. & - \\
\hline [29] & $\mathrm{Y}$ & & $\begin{array}{l}\text { Dual thresholding } \\
\text { algorithm for } \\
\text { pre-processing and the } \\
\text { edge is detected by single } \\
\text { direction gradient } \\
\text { operator. Usage of the } \\
\text { noise filter to remove the } \\
\text { noise. }\end{array}$ & $\begin{array}{l}\text { The lane detection } \\
\text { algorithm insensitive } \\
\text { headlight, rear light, cars, } \\
\text { road contour signs. }\end{array}$ & $\begin{array}{l}\text { The algorithm detects the } \\
\text { straight lanes during the } \\
\text { night. }\end{array}$ & $\begin{array}{l}\text { Detection } \\
\text { Of straight lanes. }\end{array}$ & $\begin{array}{l}\text { Camera with RGB } \\
\text { channel. }\end{array}$ & $\longrightarrow$ & Custom dataset & $\begin{array}{l}\text { Suitability of the algorithm } \\
\text { for different types of roads } \\
\text { during night to be studied. }\end{array}$ \\
\hline [30] & $\mathrm{Y}$ & & $\begin{array}{l}\text { Determination of region } \\
\text { of interest and conversion } \\
\text { of binary image via } \\
\text { adaptive threshold. }\end{array}$ & Better accuracy & $\begin{array}{l}\text { The algorithm needs } \\
\text { changes for checking its } \\
\text { suitability for the day time } \\
\text { lane detection }\end{array}$ & $\begin{array}{l}90 \% \text { accuracy during night } \\
\text { at isolated highways }\end{array}$ & $\begin{array}{l}\text { Firewire } 5400 \\
\text { camera and } \\
\text { MATLAB }\end{array}$ & $\begin{array}{c}\text { Geometrics } \\
\text { transformation of } \\
\text { image for } \\
\text { increasing the } \\
\text { accuracy and } \\
\text { intensity } \\
\text { normalization. }\end{array}$ & Custom dataset & $\begin{array}{l}\text { The constraints and } \\
\text { assumption considered do } \\
\text { not suit for the day time. }\end{array}$ \\
\hline
\end{tabular}


Table 3. Cont.

\begin{tabular}{|c|c|c|c|c|c|c|c|c|c|c|}
\hline \multirow[b]{2}{*}{ Sources } & \multicolumn{2}{|c|}{ Data } & \multirow[b]{2}{*}{ Method Used } & \multirow[b]{2}{*}{ Advantages } & \multirow[b]{2}{*}{ Drawbacks } & \multirow[b]{2}{*}{ Results } & \multirow[b]{2}{*}{ Tool Used } & \multirow[b]{2}{*}{ Future Prospects } & \multirow[b]{2}{*}{ Data } & \multirow[b]{2}{*}{ Reason for Drawbacks } \\
\hline & 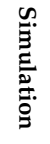 & $\stackrel{\pi}{\overparen{0}}$ & & & & & & & & \\
\hline [31] & $\mathrm{Y}$ & & $\begin{array}{l}\text { Canny edge detector } \\
\text { algorithm is used to } \\
\text { detect the edges of the } \\
\text { lanes. }\end{array}$ & $\begin{array}{l}\text { Hough transform improves } \\
\text { the output of the lane } \\
\text { tracker. }\end{array}$ & - & $\begin{array}{l}\text { Performance of the } \\
\text { proposed system is better. }\end{array}$ & $\begin{array}{l}\text { Raspberry pi } \\
\text { based robust } \\
\text { with camera } \\
\text { and sensors. }\end{array}$ & $\begin{array}{l}\text { Simulation of the } \\
\text { proposed method by } \\
\text { using raspberry Pi based } \\
\text { robot with a monocular } \\
\text { camera and radar-based } \\
\text { sensors to determine the } \\
\text { distance between } \\
\text { neighboring vehicles. }\end{array}$ & Custom data & - \\
\hline [32] & $\mathrm{Y}$ & & $\begin{array}{l}\text { Video processing } \\
\text { technique to determine } \\
\text { the lanes illumination } \\
\text { change on the region of } \\
\text { interest. }\end{array}$ & - & - & Robust performance & $\begin{array}{l}\text { vision-based } \\
\text { vehicle }\end{array}$ & $\begin{array}{l}\text { Determine the lanes } \\
\text { illumination changes on } \\
\text { the region of interest for } \\
\text { curve line roads }\end{array}$ & Simulator & - \\
\hline [33] & $\mathrm{Y}$ & Y & $\begin{array}{l}\text { A colour-based lane } \\
\text { detection and } \\
\text { representative line } \\
\text { extraction algorithm is } \\
\text { used. }\end{array}$ & $\begin{array}{l}\text { Better accuracy in the day } \\
\text { time. }\end{array}$ & $\begin{array}{l}\text { Algorithm needs changes to } \\
\text { test in different scenario. }\end{array}$ & $\begin{array}{l}\text { The results show that the } \\
\text { lane detection rate is more } \\
\text { than } 93 \% \text {. }\end{array}$ & MATLAB & $\begin{array}{l}\text { There is scope to test the } \\
\text { algorithm in the night } \\
\text { time. }\end{array}$ & Custom data & $\begin{array}{l}\text { Unwanted noise reduces } \\
\text { the performance of the } \\
\text { algorithm. }\end{array}$ \\
\hline [35] & & Y & $\begin{array}{l}\text { Proposed a lane detection } \\
\text { methodology in a circular } \\
\text { arc or parabolic based } \\
\text { geometric method. }\end{array}$ & $\begin{array}{l}\text { Video sensor improves the } \\
\text { performance of the lane } \\
\text { marking. }\end{array}$ & $\begin{array}{l}\text { Performance dropped in } \\
\text { lane detection when } \\
\text { entering the tunnel region }\end{array}$ & $\begin{array}{l}\text { Experiment performed with } \\
\text { different road scene and } \\
\text { provided better results. }\end{array}$ & $\begin{array}{l}\text { maps, video } \\
\text { sensors, GPS. }\end{array}$ & $\begin{array}{l}\text { Proposed method can test } \\
\text { with previously available } \\
\text { data. }\end{array}$ & Custom & Due to low illumination \\
\hline [36] & $\mathrm{Y}$ & & $\begin{array}{l}\text { Proposed a hierarchical } \\
\text { lane detection system to } \\
\text { detect the lanes on the } \\
\text { structured and } \\
\text { unstructured roads. }\end{array}$ & Quick detection of lanes. & - & $\begin{array}{l}\text { The system achieves an } \\
\text { accuracy of } 97 \% \text { in lane } \\
\text { detection. }\end{array}$ & MATLAB & $\begin{array}{l}\text { Algorithm can test on an } \\
\text { isolated highway, urban } \\
\text { roads. }\end{array}$ & & - \\
\hline [37] & & $\mathrm{Y}$ & $\begin{array}{l}\text { LIDAR sensor-based } \\
\text { boundary detection and } \\
\text { tracking method for } \\
\text { structured and } \\
\text { unstructured roads. }\end{array}$ & $\begin{array}{l}\text { Regardless of road types, } \\
\text { algorithm detect accurate } \\
\text { lane boundaries. }\end{array}$ & $\begin{array}{l}\text { Difficult to track lane } \\
\text { boundaries for } \\
\text { unstructured roads because } \\
\text { of low contract, arbitrary } \\
\text { road shape }\end{array}$ & $\begin{array}{l}\text { The road boundary } \\
\text { detection accuracy is } 95 \% \\
\text { for structured roads and } \\
92 \% \text { for unstructured roads. }\end{array}$ & $\begin{array}{c}\text { Test vehicle } \\
\text { with LIDAR, } \\
\text { GPS and IMU. }\end{array}$ & $\begin{array}{l}\text { Algorithm needs to test } \\
\text { with RADAR based and } \\
\text { vision-based sensors. }\end{array}$ & Custom data & $\begin{array}{l}\text { Low contract arbitrary } \\
\text { road shape }\end{array}$ \\
\hline
\end{tabular}


Table 3. Cont

\begin{tabular}{|c|c|c|c|c|c|c|c|c|c|c|}
\hline \multirow[b]{2}{*}{ Sources } & \multicolumn{2}{|c|}{ Data } & \multirow[b]{2}{*}{ Method Used } & \multirow[b]{2}{*}{ Advantages } & \multirow[b]{2}{*}{ Drawbacks } & \multirow[b]{2}{*}{ Results } & \multirow[b]{2}{*}{ Tool Used } & \multirow[b]{2}{*}{ Future Prospects } & \multirow[b]{2}{*}{ Data } & \multirow[b]{2}{*}{ Reason for Drawbacks } \\
\hline & 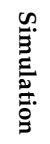 & $\underset{\overparen{D}}{\stackrel{\pi}{\mathscr{D}}}$ & & & & & & & & \\
\hline [38] & Y & & $\begin{array}{l}\text { Proposed a method to } \\
\text { detect the pedestrian } \\
\text { lanes under different } \\
\text { illumination conditions } \\
\text { with no lane markings. }\end{array}$ & $\begin{array}{l}\text { Robust performance for } \\
\text { pedestrian lane detection } \\
\text { under unstructured } \\
\text { environment. }\end{array}$ & $\begin{array}{l}\text { More challenging for indoor } \\
\text { and outdoor environment. }\end{array}$ & $\begin{array}{l}\text { The result shows that the } \\
\text { lane detection accuracy is } \\
95 \% \text {. }\end{array}$ & MATLAB & $\begin{array}{l}\text { There is scope for } \\
\text { structured roads } \\
\text { with different } \\
\text { speeds limit }\end{array}$ & $\begin{array}{l}\text { New dataset of } \\
2000 \text { images } \\
\text { (custom) }\end{array}$ & Complex environment \\
\hline [39] & $\mathrm{Y}$ & $\mathrm{Y}$ & $\begin{array}{l}\text { The proposed system is } \\
\text { implemented using an } \\
\text { improved Hough } \\
\text { transform, which } \\
\text { pre-process different light } \\
\text { intensity road images } \\
\text { and convert it to the polar } \\
\text { angle constraint area. }\end{array}$ & $\begin{array}{l}\text { Robust performance for a } \\
\text { campus road, in which the } \\
\text { road does not have lane } \\
\text { markings. }\end{array}$ & $\begin{array}{l}\text { Performance drops due to } \\
\text { low intensity of light }\end{array}$ & - & $\begin{array}{l}\text { Test vehicle and } \\
\text { MATLAB }\end{array}$ & $\longrightarrow$ & Custom data & Low illumination \\
\hline [40] & $\mathrm{Y}$ & & $\begin{array}{l}\text { A lane detection } \\
\text { algorithm based on } \\
\text { camera and 2D LIDAR } \\
\text { input data. }\end{array}$ & $\begin{array}{l}\text { Computational and } \\
\text { experimental results show } \\
\text { the method significantly } \\
\text { increases accuracy. }\end{array}$ & - & $\begin{array}{l}\text { The proposed approach } \\
\text { shows better accuracy } \\
\text { compared with the } \\
\text { traditional methods for } \\
\text { distance less than } 9 \mathrm{~m} .\end{array}$ & $\begin{array}{l}\text { Proposed method } \\
\text { need to test with } \\
\text { RADAR and } \\
\text { vision-based } \\
\text { sensors data }\end{array}$ & $\begin{array}{l}\text { software based } \\
\text { analysis and } \\
\text { MATLAB }\end{array}$ & $\begin{array}{l}\text { Fusion of } \\
\text { camera and 2D } \\
\text { LIDAR data }\end{array}$ & - \\
\hline
\end{tabular}


Table 4. A comprehensive summary of learning-based model predictive controller lane detection and tracking.

\begin{tabular}{|c|c|c|c|c|c|c|c|c|c|c|}
\hline \multirow[b]{2}{*}{ Sources } & \multicolumn{2}{|c|}{ Data } & \multirow[b]{2}{*}{ Method } & \multirow[b]{2}{*}{ Advantages } & \multirow[b]{2}{*}{ Drawbacks } & \multirow[b]{2}{*}{ Result } & \multirow[b]{2}{*}{ Tool Used } & \multirow[b]{2}{*}{ Future Prospects } & \multirow[b]{2}{*}{ Data } & \multirow[b]{2}{*}{ Reason for Drawback } \\
\hline & 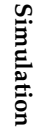 & $\underset{\pi}{\pi}$ & & & & & & & & \\
\hline [42] & & $\mathrm{Y}$ & $\begin{array}{l}\text { Gradient cue, color cue } \\
\text { and line clustering are } \\
\text { used to verify the lane } \\
\text { markings. }\end{array}$ & $\begin{array}{l}\text { The proposed method } \\
\text { works better under } \\
\text { different weather } \\
\text { conditions such as rainy } \\
\text { and snowy environments. }\end{array}$ & $\begin{array}{l}\text { The suitability of the } \\
\text { algorithm for multi-lane } \\
\text { detection of lane curvature } \\
\text { is to be studied. }\end{array}$ & $\begin{array}{l}\text { Except rainy condition } \\
\text { during the day, the } \\
\text { proposed system provides } \\
\text { better results. }\end{array}$ & $\begin{array}{l}\mathrm{C}++ \text { and OpenCV on } \\
\text { ubuntu operating } \\
\text { system. } \\
\text { Hardware: duel ARM } \\
\text { cortex-A9 processors. }\end{array}$ & - & $\begin{array}{l}48 \text { video clips } \\
\text { from USA and } \\
\text { Korea }\end{array}$ & $\begin{array}{l}\text { Since the road } \\
\text { environment may not } \\
\text { be predictable, leads to } \\
\text { false detection. }\end{array}$ \\
\hline [43] & $\mathrm{Y}$ & & $\begin{array}{l}\text { Extraction of lanes from } \\
\text { the captured image } \\
\text { Random, sample } \\
\text { consensus algorithm is } \\
\text { used to eradicate error in } \\
\text { lane detection. }\end{array}$ & $\begin{array}{l}\text { Multilane detection even } \\
\text { during poor lane markings. } \\
\text { No prior knowledge about } \\
\text { the lane is required. }\end{array}$ & $\begin{array}{l}\text { Urban driving scenario } \\
\text { quality has to be improved } \\
\text { in cardova } 2 \text { dataset since it } \\
\text { perceives the curb of the } \\
\text { sidewalk as a lane. }\end{array}$ & $\begin{array}{c}\text { The Caltech lane datasets } \\
\text { consisting of four types of } \\
\text { urban driving scenarios: } \\
\text { Cordova 1; } \\
\text { Cordova 2; } \\
\text { Washington2; with a total of } \\
1224 \text { frames containing } 4172 \\
\text { lane markings. }\end{array}$ & MATLAB & $\begin{array}{l}\text { Real time } \\
\text { implementation of } \\
\text { the proposed } \\
\text { algorithm }\end{array}$ & $\begin{array}{l}\text { Data from south } \\
\text { Korea road and } \\
\text { Caltech dataset. }\end{array}$ & $\begin{array}{l}\text { IMU sensors could be } \\
\text { incorporated to avoid } \\
\text { the false detection of } \\
\text { lanes. }\end{array}$ \\
\hline [44] & Y & $\mathrm{Y}$ & $\begin{array}{l}\text { Rectangular detection } \\
\text { region is formed on the } \\
\text { image. Edge points of } \\
\text { lane is extracted using } \\
\text { threshold algorithm. A } \\
\text { modified Brenham line } \\
\text { voting space is used to } \\
\text { detect lane segment. }\end{array}$ & $\begin{array}{l}\text { Robust lane detection } \\
\text { method by using a } \\
\text { monocular camera in which } \\
\text { the roads are provided with } \\
\text { proper lane markings. }\end{array}$ & $\begin{array}{l}\text { Performance drops when } \\
\text { road is not flat }\end{array}$ & $\begin{array}{l}\text { In Cardova } 2 \text { dataset, the } \\
\text { false detection value is } \\
\text { higher around } 38 \% \text {. The } \\
\text { algorithm shows better } \\
\text { performance under } \\
\text { different roads geometries } \\
\text { such as straight, curve, } \\
\text { polyline and complex }\end{array}$ & $\begin{array}{c}\text { Software based } \\
\text { performance analysis } \\
\text { on Caltech dataset for } \\
\text { different urban driving } \\
\text { scenario. Hardware } \\
\text { implementation on the } \\
\text { Tuyou autonomous } \\
\text { vehicle. }\end{array}$ & - & $\begin{array}{l}\text { Caltech and } \\
\text { custom-made } \\
\text { dataset }\end{array}$ & $\begin{array}{l}\text { Due to the difficulty } \\
\text { In image capturing } \\
\text { false detection } \\
\text { happened. More } \\
\text { training or inclusion of } \\
\text { sensors for live dataset } \\
\text { collection will help to } \\
\text { mitigate it. }\end{array}$ \\
\hline [45] & & $\mathrm{Y}$ & $\begin{array}{l}\text { Based on voting map, } \\
\text { detected vanishing } \\
\text { points, usage of distinct } \\
\text { property of lane colour to } \\
\text { obtain illumination } \\
\text { invariant lane marker } \\
\text { and finally found main } \\
\text { lane by using clustering } \\
\text { methods. }\end{array}$ & $\begin{array}{l}\text { Overall method test } \\
\text { algorithm within } 33 \text { ms per } \\
\text { frame. }\end{array}$ & $\begin{array}{l}\text { Need to reduce } \\
\text { computational complexity } \\
\text { by using vanishing point } \\
\text { and adaptive ROI for every } \\
\text { frame. }\end{array}$ & $\begin{array}{c}\text { Under various } \\
\text { Illumination condition lane } \\
\text { detection rate of the } \\
\text { algorithm is an average } 93 \%\end{array}$ & $\begin{array}{l}\text { Software based } \\
\text { analysis done. }\end{array}$ & $\begin{array}{l}\text { There are chances, } \\
\text { to test algorithm } \\
\text { at day time with } \\
\text { inclement weather } \\
\text { conditions. }\end{array}$ & $\begin{array}{l}\text { Custom data } \\
\text { based on } \\
\text { Real-time }\end{array}$ & - \\
\hline [46] & Y & & $\begin{array}{l}\text { Proposed a sharp curve } \\
\text { lane from the input } \\
\text { image based on } \\
\text { hyperbola fitting. The } \\
\text { input image is converted } \\
\text { to grayscale image and } \\
\text { the feature namely left } \\
\text { edge, right edge and the } \\
\text { extreme points of the } \\
\text { lanes are calculated }\end{array}$ & $\begin{array}{l}\text { Better accuracy for sharp } \\
\text { curve lanes. }\end{array}$ & $\begin{array}{l}\text { The suitability of the } \\
\text { algorithm for different road } \\
\text { geometrics yet to study. }\end{array}$ & $\begin{array}{l}\text { The results show that the } \\
\text { accuracy of lane detection is } \\
\text { around } 97 \% \text { and the } \\
\text { average time taken to detect } \\
\text { the lane is } 20 \mathrm{~ms} \text {. }\end{array}$ & $\begin{array}{l}\text { Custom made } \\
\text { simulator } C / C++ \text { and } \\
\text { visual studio }\end{array}$ & - & Custom data & - \\
\hline
\end{tabular}


Table 4. Cont.

\begin{tabular}{|c|c|c|c|c|c|c|c|c|c|}
\hline \multirow[b]{2}{*}{ Sources } & Data & \multirow[b]{2}{*}{ Method } & \multirow[b]{2}{*}{ Advantages } & \multirow[b]{2}{*}{ Drawbacks } & \multirow[b]{2}{*}{ Result } & \multirow[b]{2}{*}{ Tool Used } & \multirow[b]{2}{*}{ Future Prospects } & \multirow[b]{2}{*}{ Data } & \multirow[b]{2}{*}{ Reason for Drawback } \\
\hline & 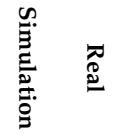 & & & & & & & & \\
\hline [47] & Y & $\begin{array}{l}\text { vanishing point detection } \\
\text { method for unstructured } \\
\text { roads }\end{array}$ & $\begin{array}{l}\text { Accurate and robust } \\
\text { performance for } \\
\text { unstructured roads. }\end{array}$ & $\begin{array}{l}\text { Difficult to obtain robust } \\
\text { vanishing point for } \\
\text { detection of lane for } \\
\text { unstructured scene. }\end{array}$ & $\begin{array}{l}\text { The accuracy of vanishing } \\
\text { point range between } 80.9 \% \\
\text { to } 93.6 \% \text { for different } \\
\text { scenarios. }\end{array}$ & $\begin{array}{l}\text { Unmanned ground } \\
\text { vehicle and mobile } \\
\text { robot. }\end{array}$ & $\begin{array}{c}\text { Future scope for } \\
\text { structured roads } \\
\text { with different } \\
\text { scenarios. }\end{array}$ & Custom data & $\begin{array}{l}\text { Complex background } \\
\text { interference and } \\
\text { unclear road marking }\end{array}$ \\
\hline [48] & Y & $\begin{array}{l}\text { Proposed a lane detection } \\
\text { approach using Gaussian } \\
\text { distribution random } \\
\text { sample consensus } \\
\text { (G-RANSAC), usage of } \\
\text { rider detector to extract } \\
\text { the features of lane points } \\
\text { and adaptable neural } \\
\text { network for remove } \\
\text { noise. }\end{array}$ & $\begin{array}{l}\text { Provides better results } \\
\text { during the presence of } \\
\text { vehicle shadow and } \\
\text { minimal illumination of the } \\
\text { environment. }\end{array}$ & - & $\begin{array}{l}\text { The proposed algorithm is } \\
\text { tested under different } \\
\text { illumination condition } \\
\text { ranging from normal, } \\
\text { intense, normal and poor } \\
\text { and provides lane detection } \\
\text { accuracy as } 95 \%, 92 \%, 91 \% \\
\text { and } 90 \% \text {. }\end{array}$ & $\begin{array}{l}\text { Software based } \\
\text { analysis }\end{array}$ & $\begin{array}{l}\text { Need to test } \\
\text { proposed method } \\
\text { under various } \\
\text { times like day, } \\
\text { night. }\end{array}$ & Test vehicle & - \\
\hline
\end{tabular}

Table 5. A comprehensive summary of robust lane detection and tracking.

\begin{tabular}{|c|c|c|c|c|c|c|c|c|c|c|}
\hline \multirow[b]{2}{*}{ Sources } & \multicolumn{2}{|c|}{ Data } & \multirow[b]{2}{*}{ Method Used } & \multirow[b]{2}{*}{ Advantages } & \multirow[b]{2}{*}{ Drawbacks } & \multirow[b]{2}{*}{ Result } & \multirow[b]{2}{*}{ Tool Used } & \multirow[b]{2}{*}{ Future Prospects } & \multirow[b]{2}{*}{ Data } & \multirow[b]{2}{*}{$\begin{array}{l}\text { Reason for } \\
\text { Drawbacks }\end{array}$} \\
\hline & 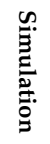 & $\underset{\overparen{D}}{\stackrel{\pi}{\mathscr{D}}}$ & & & & & & & & \\
\hline [49] & & Y & $\begin{array}{l}\text { Inverse perspective } \\
\text { mapping method is } \\
\text { applied to convert the } \\
\text { image to bird's eye view. }\end{array}$ & Quick detection of lane. & $\begin{array}{l}\text { The algorithm performance } \\
\text { drops due to the fluctuation } \\
\text { in the lighting conditions. }\end{array}$ & $\begin{array}{l}\text { The lane detection } \\
\text { error is } 5 \% \text {. The } \\
\text { cross-track error is } 25 \% \\
\text { lane detection time is } \\
11 \mathrm{~ms} \text {. }\end{array}$ & $\begin{array}{l}\text { Fisheye dashcam: } \\
\text { inertial measurement } \\
\text { unit; Arm } \\
\text { processor-based } \\
\text { computer. }\end{array}$ & $\begin{array}{l}\text { Enhancing the algorithm } \\
\text { suitable for complex road } \\
\text { scenario and with less } \\
\text { light conditions. }\end{array}$ & $\begin{array}{c}\text { Data obtained } \\
\text { by using a } \\
\text { model car } \\
\text { running at a } \\
\text { speed of } 1 \mathrm{~m} / \mathrm{s}\end{array}$ & $\begin{array}{c}\text { The complex } \\
\text { environment creates } \\
\text { unnecessary tilt } \\
\text { causing some } \\
\text { inaccuracy in lane } \\
\text { detection. }\end{array}$ \\
\hline
\end{tabular}


Table 5. Cont.

\begin{tabular}{|c|c|c|c|c|c|c|c|c|c|c|}
\hline \multirow[b]{2}{*}{ Sources } & \multicolumn{2}{|c|}{ Data } & \multirow[b]{2}{*}{ Method Used } & \multirow[b]{2}{*}{ Advantages } & \multirow[b]{2}{*}{ Drawbacks } & \multirow[b]{2}{*}{ Result } & \multirow[b]{2}{*}{ Tool Used } & \multirow[b]{2}{*}{ Future Prospects } & \multirow[b]{2}{*}{ Data } & \multirow[b]{2}{*}{$\begin{array}{l}\text { Reason for } \\
\text { Drawbacks }\end{array}$} \\
\hline & .?. & 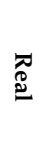 & & & & & & & & \\
\hline [50] & Y & & $\begin{array}{l}\text { Deep learning-based } \\
\text { reinforcement learning is } \\
\text { used for decision making } \\
\text { in the changeover. The } \\
\text { reward for decision } \\
\text { making is based on the } \\
\text { parameters like traffic } \\
\text { efficiency }\end{array}$ & $\begin{array}{l}\text { Cooperative } \\
\text { decision-making processes } \\
\text { involving the reward } \\
\text { function comparing delay } \\
\text { of a vehicle and traffic. }\end{array}$ & $\begin{array}{l}\text { Validation expected to } \\
\text { check the accuracy of the } \\
\text { lane changing algorithm for } \\
\text { heterogeneous environment }\end{array}$ & $\begin{array}{l}\text { The performance is } \\
\text { fine-tuned based on } \\
\text { the cooperation for } \\
\text { both accident and } \\
\text { non-accidental } \\
\text { scenario }\end{array}$ & $\begin{array}{l}\text { Custom made } \\
\text { simulator }\end{array}$ & $\begin{array}{l}\text { Dynamic selection of } \\
\text { cooperation coefficient } \\
\text { under different traffic } \\
\text { scenario }\end{array}$ & $\begin{array}{l}\text { Newell car } \\
\text { following } \\
\text { model. }\end{array}$ & - \\
\hline [51] & Y & & $\begin{array}{l}\text { Reinforcement } \\
\text { learning-based approach } \\
\text { for decision making by } \\
\text { using Q-function } \\
\text { approximator. }\end{array}$ & $\begin{array}{l}\text { Decision-making process } \\
\text { involving reward function } \\
\text { comprising yaw rate, yaw } \\
\text { acceleration and lane } \\
\text { changing time. }\end{array}$ & $\begin{array}{l}\text { Need for more testing to } \\
\text { check the efficiency of the } \\
\text { approximator function for } \\
\text { its suitability under } \\
\text { different real-time } \\
\text { conditions. }\end{array}$ & $\begin{array}{l}\text { The reward functions } \\
\text { are used to learn the } \\
\text { lane in a better way. }\end{array}$ & $\begin{array}{l}\text { Custom made } \\
\text { simulator }\end{array}$ & $\begin{array}{l}\text { To test the efficiency of } \\
\text { the proposed approach } \\
\text { under different road } \\
\text { geometrics and traffic } \\
\text { conditions. Testing the } \\
\text { feasibility of the } \\
\text { reinforcement learning } \\
\text { with fuzzy logic for } \\
\text { image input and } \\
\text { controller action based on } \\
\text { the current situation. }\end{array}$ & custom & $\begin{array}{l}\text { More parameters } \\
\text { could be considered } \\
\text { for the reward } \\
\text { function. }\end{array}$ \\
\hline [52] & Y & & $\begin{array}{l}\text { Probabilistic and } \\
\text { prediction for the } \\
\text { complex driving scenario. }\end{array}$ & $\begin{array}{l}\text { Usage of deterministic and } \\
\text { probabilistic prediction of } \\
\text { traffic of other vehicles to } \\
\text { improve the robustness }\end{array}$ & $\begin{array}{l}\text { Analysis of the efficiency of } \\
\text { the system under real-time } \\
\text { noise is challenging. }\end{array}$ & $\begin{array}{l}\text { Robust decision } \\
\text { making compared to } \\
\text { the deterministic } \\
\text { method. Lesser } \\
\text { probability of collision. }\end{array}$ & $\begin{array}{l}\text { MATLAB/Simulink } \\
\text { and carsim. Used } \\
\text { real-time setup as } \\
\text { following: } \\
\text { Hyundai-Kia motors } \\
\text { K7, mobile eye camera } \\
\text { system, micro auto box } \\
\text { II, Delphi radars, IBEO } \\
\text { laser scanner. }\end{array}$ & $\begin{array}{l}\text { Testing undue different } \\
\text { scenario }\end{array}$ & $\begin{array}{l}\text { Custom dataset } \\
\text { (collection of } \\
\text { data using test } \\
\text { vehicle). }\end{array}$ & $\begin{array}{l}\text { The algorithm to be } \\
\text { modified for real } \\
\text { suitability for } \\
\text { real-time } \\
\text { monitoring. }\end{array}$ \\
\hline [53] & Y & & $\begin{array}{l}\text { Usage of pixel hierarchy } \\
\text { to the occurrence of lane } \\
\text { markings. Detection of } \\
\text { the lane markings using a } \\
\text { boosting algorithm. } \\
\text { Tracking of lanes using a } \\
\text { particle filter. }\end{array}$ & $\begin{array}{l}\text { Detection of the lane } \\
\text { without prior knowledge } \\
\text { on-road model and vehicle } \\
\text { speed. }\end{array}$ & $\begin{array}{l}\text { Usage of vehicles inertial } \\
\text { sensors GPS information } \\
\text { and geometry model } \\
\text { further improve } \\
\text { performance under } \\
\text { different environmental } \\
\text { conditions }\end{array}$ & $\begin{array}{l}\text { Improved performance } \\
\text { by using support } \\
\text { vector machines and } \\
\text { artificial neural } \\
\text { networks on the image. }\end{array}$ & $\begin{array}{l}\text { Machine with 4-GHz } \\
\text { processor capable of } \\
\text { working on image } \\
\text { approximately } 240 \times \\
320 \text { image at } 15 \text { frames } \\
\text { per second. }\end{array}$ & $\begin{array}{l}\text { To test the efficiency of } \\
\text { the algorithm by using } \\
\text { the Kalman filter. }\end{array}$ & custom data & $\begin{array}{l}\text { Calibration of the } \\
\text { sensors needs to be } \\
\text { maintained. }\end{array}$ \\
\hline
\end{tabular}


Based on the review, some of the key observations from Tables 3-5 are summarized below:

- Frequent calibration is required for accurate decision making in a complex environment.

- Reinforcement learning with the model predictive control could be a better choice to avoid false lane detection.

- Model-based approaches (robust lane detection and tracking) provide better results in different environmental conditions. Camera quality plays an important role in determining lane marking.

- The algorithm's performance depends on the type of filter used, and the Kalman filter is mostly used for lane tracking.

- In a vision-based system, image smoothing is the initial lane detection and tracking stage, which plays a vital role in increasing systems performance.

- External disturbances like weather conditions, vision quality, shadow and blazing, and internal disturbances such as too narrow, too wide, and unclear lane marking, drop algorithm performance.

- $\quad$ The majority of researchers ( $>90 \%$ ) have used custom datasets for research.

- Monocular, stereo and infrared cameras have been used to capture images and videos. The algorithm's accuracy depends on the type of camera used, and a stereo camera gives better performance than a monocular camera.

- The lane markers can be occluded by a nearby vehicle while doing overtake.

- There is an abrupt change in illumination as the vehicle gets out of a tunnel. Sudden changes in illumination affect the image quality and drop the system performance.

- The results show that the lane detection and tracking efficiency rate under dry and light rain conditions is near $99 \%$ in most scenarios. However, the efficiency of lane marking detection is significantly affected by heavy rain conditions.

- It has been seen that the performance of the system drops due to unclear and degraded lane markings.

- IMU (Inertia measurement unit) and GPS are examples that help to improve RADAR and LIDAR's performance of distance measurement.

- One of the biggest problems with today's ADAS is that changes in environmental and weather conditions have a major effect on the system's performance.

\subsection{Patented Works}

According to the patent's family size, it is observed that Toyota has a generally greater number of patents work (521), followed by Ford (406), General Motors (GM) (353), Honda motor (284) and Uber (245). Six of the top ten companies are from the United States, while four are from Asia. From a patent standpoint, Europe seems to be lagging behind in the battle for ADAS, and that the patents published in China and other Asian countries for lane detection and tracking are invented in the universities. Only Google and General Motor patent portfolios have a high technical relevance score among the top ten patent manufacturers. On the other hand, all portfolios have an above average market coverage score, indicating that their manufacturer believes their inventions are valuable enough to protect globally, and it highlights the significance and promises that companies perceive in autonomous driving. The detailed review of the patent works is beyond the scope of this study. However, given the commercial nature of lane detection and tracking, a sample of patented works, especially from the vehicle manufacturer, that align with the three approaches (feature-based, learning-based and model-based) has been presented in Table 6 . Some of the key observations from Table 6 are: 
- By following the method of image and sensor-based lane detection, separate courses are calculated for precisely two of the lane markings to be tracked, with a set of binary parameters indicating the allocation of the determined offset values to one of the two separate courses [54]

- By following the robust lane detection and tracking method, after a fixed number of computing cycles, a most probable hypothesis is calculated — the difference between the predicted courses of lane markings to only be tracked and the courses of recognized lane markings to be lowest [55].

- A parametric estimation method, in particular a maximum likelihood method, is used to assign the calculated offset values to each of the separate courses of the lane markings to be tracked [56].

- Only those two-lane markers that refer to the left and right lane boundaries of the vehicle's own lane are applied to the tracking procedure [57].

- The positive and negative ratios of the extracted characteristics of the frame are used to assess the system's correctness. The degree of accuracy is enhanced by including the judgment in all extracted frames [58].

- At a present calculation cycle, the lane change assistance calculates a target control amount comprising a feed-forward control using a target curvature of a track for changing the host vehicle's lane [59].

- Extra details analyzing signals mounted to determine if a collision between the host vehicle and any other vehicle is likely to occur, allowing action to be done to avoid the accident [60].

- There are two kinds of issues that are often seen and corrected in dewarped perspective images: a stretching effect at the periphery region of a wide-angle image de warped by rectilinear projection, and duplicate images of objects in an area where the left and right camera views overlap [61].

- The object identification system examines the pixels in order to identify the object that has not previously been identified in the 3D Environment [62].

Table 6. Summary of patents for lane detection and tracking algorithms.

\begin{tabular}{|c|c|c|c|c|c|c|}
\hline Country & Patent No & Assignee & Method & Key Finding & Approach & Inventor \\
\hline USA & US20170068862A1 & $\begin{array}{c}\text { Aptiv } \\
\text { Technologies Ltd. }\end{array}$ & $\begin{array}{l}\text { Camera based vision based } \\
\text { driver assistance system. }\end{array}$ & $\begin{array}{l}\text { State estimation and } \\
\text { separate progression. }\end{array}$ & $\begin{array}{l}\text { Feature based } \\
\text { approach }\end{array}$ & Mirko Mueter, Kun Zhao \\
\hline USA & US9384394B2 & $\begin{array}{l}\text { Toyota motor } \\
\text { corporation }\end{array}$ & $\begin{array}{c}\text { Generates accurate lane } \\
\text { estimation using course map } \\
\text { information and LIDAR } \\
\text { sensors. }\end{array}$ & $\begin{array}{l}\text { Centre of the lane and } \\
\text { multiple lanes. }\end{array}$ & $\begin{array}{l}\text { Model based } \\
\text { approach }\end{array}$ & $\begin{array}{l}\text { Avdhut Joshi and } \\
\text { Michael James }\end{array}$ \\
\hline USA & US20020095246A1 & $\begin{array}{l}\text { Nissan motor co } \\
\text { Ltd. }\end{array}$ & $\begin{array}{l}\text { Controller is designed in } \\
\text { such way that it detect lanes } \\
\text { by controlling steering angle } \\
\text { when vehicle move out of } \\
\text { desired track. }\end{array}$ & $\begin{array}{l}\text { Measure the output of the } \\
\text { signal. }\end{array}$ & $\begin{array}{l}\text { Learning based } \\
\text { approach }\end{array}$ & Hiroshi Kawazoe \\
\hline Europe & EP1143398A3 & $\begin{array}{l}\text { Panasonic } \\
\text { Corporation }\end{array}$ & $\begin{array}{l}\text { Proposed an extraction } \\
\text { method using Hough } \\
\text { transform to detect the lanes } \\
\text { in the opposite side of roads. }\end{array}$ & $\begin{array}{l}\text { Determine the maximum } \\
\text { value of accumulators. }\end{array}$ & $\begin{array}{l}\text { Feature based } \\
\text { approach }\end{array}$ & $\begin{array}{c}\text { Atsushi Lisaka, Mamoru } \\
\text { Kaneko and Nobohiko } \\
\text { Yasui }\end{array}$ \\
\hline China & CN105205500A & $\begin{array}{l}\text { Beijing University } \\
\text { of post and } \\
\text { telecommunication }\end{array}$ & $\begin{array}{l}\text { Computer graphical and } \\
\text { vision-based technology with } \\
\text { multi target filtering and } \\
\text { sorter training is used. }\end{array}$ & $\begin{array}{l}\text { This method finds multi } \\
\text { target tracking and cascade } \\
\text { classifier with high } \\
\text { detection processing } \\
\text { speed. }\end{array}$ & $\begin{array}{l}\text { Model based } \\
\text { approach }\end{array}$ & $\begin{array}{c}\text { Zhitong, H. and Yuefeng, } \\
\text { Z }\end{array}$ \\
\hline Japan & JP6589941B2 & Not available & $\begin{array}{l}\text { Developed steering assist } \\
\text { device for lane detection and } \\
\text { tracking under periphery } \\
\text { monitoring. }\end{array}$ & $\begin{array}{l}\text { Objective of this method is } \\
\text { relative position host } \\
\text { vehicle and their relation } \\
\text { with lane has been } \\
\text { identified. }\end{array}$ & $\begin{array}{l}\text { Model based } \\
\text { approach }\end{array}$ & Shota Fujii \\
\hline USA & US10336326 & $\begin{array}{c}\text { Ford global } \\
\text { technologies LLC }\end{array}$ & $\begin{array}{l}\text { Proposed a deep } \\
\text { learning-based front facing } \\
\text { camera lane detection } \\
\text { method. }\end{array}$ & $\begin{array}{l}\text { Exacted features of lane } \\
\text { boundaries with the help } \\
\text { of camera mounted at } \\
\text { front. }\end{array}$ & $\begin{array}{l}\text { Feature based } \\
\text { approach }\end{array}$ & $\begin{array}{c}\text { Alexandru Mihai, } \\
\text { Tejaswi Koduri, Vidya } \\
\text { Nariyambut Marali Kyle } \\
\text { J Carey }\end{array}$ \\
\hline
\end{tabular}


Table 6. Cont.

\begin{tabular}{|c|c|c|c|c|c|c|}
\hline Country & Patent No & Assignee & Method & Key Finding & Approach & Inventor \\
\hline USA & US9834143B2 & $\begin{array}{c}\text { GM Global } \\
\text { Technology } \\
\text { Operations LLC }\end{array}$ & $\begin{array}{l}\text { The improved perspective } \\
\text { view is produced a new } \\
\text { camera imaging surface } \\
\text { model and other distortion } \\
\text { correcting technique. }\end{array}$ & $\begin{array}{l}\text { Main objective is to } \\
\text { improve the perspective } \\
\text { view of the vehicle at front } \\
\text { for lane detection and } \\
\text { tracking. }\end{array}$ & $\begin{array}{c}\text { Featured based } \\
\text { approach }\end{array}$ & $\begin{array}{c}\text { Wende Zhang, Jinsong } \\
\text { Wang, Kent S Lybecker, } \\
\text { Jeffrey S. Piasecki, } \\
\text { Bakhtiar Brian Litkouhi, } \\
\text { Ryan M. Frakes }\end{array}$ \\
\hline USA & US20170323179A1 & $\begin{array}{l}\text { Uber technologies } \\
\text { Inc. }\end{array}$ & $\begin{array}{l}\text { Sensor fusion data processing } \\
\text { technique is used for } \\
\text { surrounding object detection } \\
\text { and lane detection. }\end{array}$ & $\begin{array}{c}\text { Generate 3D envirmental } \\
\text { data through sensor fusion } \\
\text { to guide autonomous } \\
\text { vehicle. }\end{array}$ & $\begin{array}{l}\text { Leaning based } \\
\text { approach }\end{array}$ & $\begin{array}{c}\text { Carlos } \\
\text { Vallespi-Gonzalez }\end{array}$ \\
\hline
\end{tabular}

\section{Discussion}

Based on the review of studies on lane detection and tracking in Section 3.2, it can be observed that there are limited data sets in the literature that researchers have used to test lane detection and tracking algorithms. Based on the literature review, a summary of the key data sets used in the literature or available to the researchers is presented in Table 7, which shows some of the key features, strengths, and weaknesses. It is expected that in future, more data sets may be available for the researchers as this field continues to grow, especially with the development of fully autonomous vehicles. As per the statistics survey of research papers published between 2000 and 2020, almost $42 \%$ of researchers mainly focused on Intrusion Detection System (IDS) matrix to evaluate the performance of the algorithms. This may be because the efficiency and effectiveness of IDS are better when compared to Point Clustering Comparison, Gaussian Distribution, Spatial Distribution and Key Points Estimation methods. The verification of the performance of the algorithms for lane detection and tracking system is done based on ground truth data set. There are four possibilities as true positive (TP), false negative (FN), false positive (FP) and true negative (TN), as shown in Table 8. There are many metrics available for the evaluation of performance, but the most common are accuracy, precision, F-score, Dice similarity coefficient (DSC) and receiver operating characteristic (ROC) curves. Table 9 provides the common metrics and the associated formulas used for the evaluation of the algorithms. 
Table 7. A summary of datasets that have been used in the literature for verification of the algorithms.

\begin{tabular}{|c|c|c|c|}
\hline Dataset & Features & Strength & Weakness \\
\hline CU lane [63] & $\begin{array}{l}55 \mathrm{~h} \text { videos, } 133,235 \text { extracted frames, } 88,880 \text { training set, } 9675 \text { validations set } \\
\text { and } 34,680 \text { test set. }\end{array}$ & $\begin{array}{l}\text { For unseen or occluded lane marking annotated } \\
\text { manually with a cubic spline. }\end{array}$ & $\begin{array}{c}\text { Except for four lanes markings, others are not } \\
\text { annotated }\end{array}$ \\
\hline Caltech [64] & $\begin{array}{l}10 \mathrm{~h} \text { video } 640 \times 480 \mathrm{~Hz} \text { of regular traffic in an urban environment. } \\
250,000 \text { frames, 350,000 boundary boxes annotated with occlusion and } \\
\text { temporal. }\end{array}$ & $\begin{array}{l}\text { Entire dataset annotated, testing data also provided } \\
\text { (set 06-set 10) and training data (set 00-set 05) each } \\
1 \text { GB. }\end{array}$ & $\begin{array}{l}\text { Not applicable for all types of road geometries and } \\
\text { weather conditions. }\end{array}$ \\
\hline $\begin{array}{l}\text { Custom data (collection of data using test } \\
\text { vehicle) }\end{array}$ & Not applicable & Available according to the requirements & Time-consuming and highly expensive \\
\hline DIML [65] & $\begin{array}{l}\text { Multimodal dataset: } \\
\text { Sony cyber shot DSC-RX } 100 \text { camera, } 5 \text { different photometric variation pairs. } \\
\text { RGB-D dataset: More than 200indoor/outdoor scenes, Kinect Vz and zed } \\
\text { stereo camera obtain RGB-D frames. } \\
\text { Lane dataset: } 470 \text { video sequences of downtown and urban roads. } \\
\text { Emotion Recognition dataset (CAER): more than 13,000 videos and 13,000 } \\
\text { annotated videos } \\
\text { CoVieW18 dataset: untrimmed videos sample, } 90,000 \text { YouTube videos URLs. }\end{array}$ & $\begin{array}{l}\text { Different scenarios have been covered, like a traffic } \\
\text { jam, pedestrians and obstacles. }\end{array}$ & $\begin{array}{l}\text { Dataset for different weather conditions and lanes } \\
\text { with no markings are missing. }\end{array}$ \\
\hline KITTI [66] & $\begin{array}{l}\text { It contains stereo, optical flow, visual odometry etc. it contains an object } \\
\text { detection dataset, monocular images and boundary boxes, } 7481 \text { training } \\
\text { images, } 7518 \text { test images. }\end{array}$ & $\begin{array}{l}\text { Evaluation is done of orientation estimation of bird's } \\
\text { eye view and applicable for real-time object detection } \\
\text { and 3D tracking. Evaluation metrics provided. }\end{array}$ & $\begin{array}{c}\text { Only } 15 \text { cars and } 30 \text { pedestrians have been considered } \\
\text { while capturing images. Applicable for rural and } \\
\text { highway roads dataset. }\end{array}$ \\
\hline Tusimple [67] & $\begin{array}{l}\text { Training: } 3222 \text { annotated vehicles in } 20 \text { frames per second for } 1074 \text { clips of } 25 \\
\text { videos. } \\
\text { Testing: } 269 \text { video clips } \\
\begin{array}{c}\text { Supplementary data: } 5066 \text { images of position and velocity of vehicle marked } \\
\text { by range sensors. }\end{array}\end{array}$ & $\begin{array}{l}\text { Lane detection challenge, velocity estimation } \\
\text { challenge and ground truths have been provided. }\end{array}$ & $\begin{array}{l}\text { Calibration file for lane detection has not been } \\
\text { provided. }\end{array}$ \\
\hline UAH [68] & $\begin{array}{c}\text { Raw real time data: } \\
\text { Raw-GPS, RAW-Accelerometers. } \\
\text { Processed data as continuous variables: pro lane detection, pro vehicle } \\
\text { detection and pro OpenStreetMap data. } \\
\text { Processed data as events: events list lane changes and events inertial. } \\
\text { Sematic information: } \\
\text { Sematic final and sematic online. }\end{array}$ & $\begin{array}{l}\text { More than } 500 \text { min naturistic driving and processed } \\
\text { sematic information have provided. }\end{array}$ & Limited accessibility to the research community \\
\hline BDD100K [69] & $\begin{array}{l}\text { 100,000 videos for more than } 1000 \mathrm{~h} \text {, road object detection, drivable area, } \\
\text { segmentation and full frame sematic segmentation. }\end{array}$ & $\begin{array}{l}\text { IMU data, timestamp and localization have been } \\
\text { included in the dataset. }\end{array}$ & Data for unstructured road has not covered. \\
\hline
\end{tabular}


Table 8. Performance metrics for verification of lane detection and tracking algorithms, compiled from ref. [70].

\begin{tabular}{ccc}
\hline Possibility & Condition $\mathbf{1}$ & Condition 2 \\
\hline True positive & Ground truth exists & When the algorithm detects lane markers. \\
\hline False positive & No ground truth exists & When the algorithm detects lane markers. \\
\hline False negative & Ground truth exists in the image & When the algorithm detects lane markers. \\
\hline True negative & No ground truth exists in the image & When the algorithm is not detecting anything \\
\hline
\end{tabular}

Table 9. A summary of the equation of metrics used for evaluation of the performance of the algorithm, compiledfrom refs. $[71,72]$.

\begin{tabular}{ccc}
\hline Sr. no & Metrics & Formula * $^{*}$ \\
\hline 1. & Accuracy(A) & $A=\frac{(T P+T N)}{(T P+T N+F P+F N)}$ \\
\hline 2. & Detection rate (DR) & $D R=\frac{(T P)}{(T P+F N)}$ \\
\hline 3. & False positive rate (FPR) & $F P R=\frac{(F N)}{(T P+F N)}$ \\
\hline 4. & False negative rate (FNR) & $F N R=\frac{F N}{(F N+T P)}$ \\
\hline 5. & True negative rate (TNR) & $T N R=\frac{T N}{(T N+T P)}$ \\
\hline 6. & Precision & Precision $=\frac{T P}{(T N+F P)}$ \\
\hline 8. & F-measure & Feasure $=\frac{(2 \times \text { Recall } \times \text { Precision })}{(\text { Recall } \times \text { Precision })}$ \\
\hline Mrror $=\frac{(T P+F N)}{(F P+F N+T P+T N)}$
\end{tabular}

${ }^{*}$ Where, $T P=$ True positive, i.e., both conditions are satisfied by the algorithm. $F P=$ False positive. i.e., only one condition satisfied by the algorithm. $T N=$ True negative. i.e., ground truth missing in the image. $F N=$ False negative. i.e., algorithm fails to detect lane marking.

If the database is balanced, the accuracy rate should accurately reflect the algorithm's global output. The precision reflects the goodness of optimistic forecasts. The greater the accuracy, the lower the number of "false alarms." The recall, also called true positive rate (TPR), is the ratio of positive instances that are correctly detected by the algorithm. Therefore, the higher the recall, the higher the algorithm's quality in detecting positive instances. The F1-Score is the Precision and Recall harmonic mean, and since they are combined into a concise metric, it can be used for comparing algorithms. Because it is more sensitive to low values, the harmonic mean is used rather than arithmetic. Hence, a valid algorithm has a satisfactory F1 score if it has accuracy and high recall. These parameters can be estimated as unique metrics for each class or as the algorithm's overall metrics [73].

Table 10 shows the SWOT analysis of different approaches used for lane detection and tracking algorithms. The use of a Learning-based approach (model predictive controller) is considered an emerging approach for lane detection and tracking because it is computationally more efficient than the other two approaches, and it provides reasonable results in real-time scenarios. However, the risk of mismatching lanes and performance drop in inclement weather conditions are the drawback of the learning-based approach. Featurebased approach, while time-consuming, can provide better performance in optimization of lane detection and tracking. However, this approach poses challenges in handling high illumination or shadows. Image and sensor-based lane detection and tracking approaches have been used widely in lane detection and tracking patents. 
Table 10. SWOT analysis of different approaches used for lane detection and tracking algorithms.

\begin{tabular}{|c|c|c|c|c|}
\hline Methods & Strength & Weakness & Opportunities & Threats \\
\hline $\begin{array}{l}\text { Feature based } \\
\text { approach }\end{array}$ & $\begin{array}{l}\text { Feature extraction is used to } \\
\text { determine false lane markings. }\end{array}$ & Time-consuming & $\begin{array}{l}\text { Better performance in } \\
\text { optimization }\end{array}$ & $\begin{array}{l}\text { Less effective for complex } \\
\text { illumination and shadow }\end{array}$ \\
\hline $\begin{array}{l}\text { Learning based } \\
\text { approach }\end{array}$ & Easy and reliable method & Mismatching lanes & $\begin{array}{c}\text { Computationally more } \\
\text { efficient }\end{array}$ & $\begin{array}{l}\text { Performance drops due to } \\
\text { inclement weather }\end{array}$ \\
\hline $\begin{array}{l}\text { Model based } \\
\text { approach }\end{array}$ & $\begin{array}{l}\text { Camera quality improves } \\
\text { system performance }\end{array}$ & $\begin{array}{l}\text { Expensive and } \\
\text { time-consuming }\end{array}$ & $\begin{array}{l}\text { Robust performance for } \\
\text { lane detection model }\end{array}$ & $\begin{array}{l}\text { Difficult to mount sensor fusion } \\
\text { system for complex geometry }\end{array}$ \\
\hline
\end{tabular}

In addition, from the literature synthesis, several gaps in knowledge are identified and are presented in Table 11. The literature review shows that clothoid and hyperbola shape roads are ignored for lane detection and algorithms road because of the complexity of road structure and unavailability of the dataset. Likewise, much work has already been done on structured roads' pavement marking compared to unstructured roads (Figure 3). Most studies focus on straight roads. It is to be noted that unstructured roads are available in residential areas, hilly area roads, forest area roads. Much research has previously considered daytime, while night and rainy conditions are less studied. From the literature, it is observed that, in terms of speed flow conditions, they have been previously researched on the speed levels of $40 \mathrm{~km} / \mathrm{h}$ to $80 \mathrm{~km} / \mathrm{h}$ while high speed (above $80 \mathrm{~km} / \mathrm{hr}$ ) has received less attention. Further, occlusion due to overtaking vehicles or other objects (Figure 4), and high illumination also pose a challenge for lane detection and tracking. These issues should be addressed to move from level 3 automation (partial driving) to level 5 fully autonomous Also, new databases for more testing of algorithms are needed as researchers are constrained due to the unavailability of datasets. There is, however, the prospect of using synthetic sensor data generated by using a test vehicle or driving scenario designing through a driving simulator app available through commercial software.

Table 11. Lane detection under different conditions to identify the gaps in knowledge.

\begin{tabular}{|c|c|c|c|c|c|c|c|c|c|}
\hline \multirow[b]{2}{*}{ 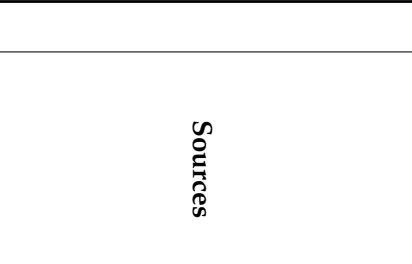 } & \multicolumn{3}{|c|}{ Road Geometry } & \multicolumn{2}{|c|}{ Pavement Marking } & \multicolumn{3}{|c|}{ Weather Condition } & \multirow[t]{2}{*}{ Speed } \\
\hline & 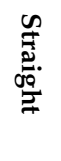 & $\begin{array}{l}\stackrel{0}{\circ} \\
\frac{\sigma}{2} \\
\frac{0}{2}\end{array}$ & 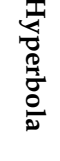 & 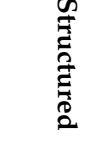 & 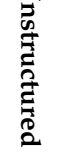 & $\underset{\mathscr{\Downarrow}}{\mathscr{\Downarrow}}$ & 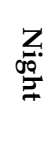 & ॠ্ّ. & \\
\hline [26] Borkar et al. (2009) & $\sqrt{ }$ & - & $\sqrt{ }$ & $\sqrt{ }$ & - & - & - & - & - \\
\hline [28] Lu et al. (2002) & $\sqrt{ }$ & - & - & $\sqrt{ }$ & - & $\sqrt{ }$ & - & - & - \\
\hline [29] Zhang \& Shi (2009) & $\sqrt{ }$ & - & - & $\sqrt{ }$ & - & - & $\sqrt{ }$ & - & - \\
\hline [32] Hong et al. (2018) & $\sqrt{ }$ & - & - & $\sqrt{ }$ & - & $\sqrt{ }$ & - & - & - \\
\hline [33] Park, H. et al. (2018) & $\sqrt{ }$ & - & - & $\sqrt{ }$ & - & $\sqrt{ }$ & - & - & $\begin{array}{l}\text { Low }(40 \mathrm{~km} / \mathrm{h}) \& \\
\text { high }(80 \mathrm{~km} / \mathrm{h})\end{array}$ \\
\hline [34] EI Hajiouji, H. (2019) & $\sqrt{ }$ & - & - & $\sqrt{ }$ & - & $\sqrt{ }$ & $\sqrt{ }$ & - & $120 \mathrm{~km} / \mathrm{h}$ \\
\hline [35] Samadzadegan et al. (2006) & - & - & $\sqrt{ }$ & $\sqrt{ }$ & - & $\sqrt{ }$ & $\sqrt{ }$ & - & - \\
\hline [36] Cheng et al. (2010) & $\sqrt{ }$ & $\sqrt{ }$ & - & $\sqrt{ }$ & - & $\sqrt{ }$ & - & - & - \\
\hline [40] Yeniaydin et al. (2019) & $\sqrt{ }$ & - & $\sqrt{ }$ & - & $\sqrt{ }$ & $\sqrt{ }$ & - & - & - \\
\hline [41] Kemsoaram et al. (2019) & $\sqrt{ }$ & - & $\sqrt{ }$ & - & $\sqrt{ }$ & - & - & - & - \\
\hline [43] Son et al. (2019) & $\sqrt{ }$ & - & $\sqrt{ }$ & $\sqrt{ }$ & - & $\sqrt{ }$ & - & - & \\
\hline [47] Chen et al. (2018) & $\sqrt{ }$ & $\sqrt{ }$ & - & $\sqrt{ }$ & - & $\sqrt{ }$ & - & - & - \\
\hline [52] Suh et al. (2019) & $\sqrt{ }$ & - & $\sqrt{ }$ & $\sqrt{ }$ & - & $\sqrt{ }$ & - & - & $60-80 \mathrm{~km} / \mathrm{h}$ \\
\hline [53] Gopalan et al. (2018) & $\sqrt{ }$ & - & $\sqrt{ }$ & $\sqrt{ }$ & $\sqrt{ }$ & $\sqrt{ }$ & - & - & - \\
\hline [74] Wu et al. (2008) & $\sqrt{ }$ & - & - & $\sqrt{ }$ & - & $\sqrt{ }$ & - & - & $40 \mathrm{~km} / \mathrm{h}$ \\
\hline
\end{tabular}


Table 11. Cont.

\begin{tabular}{|c|c|c|c|c|c|c|c|c|c|}
\hline \multirow[b]{2}{*}{ 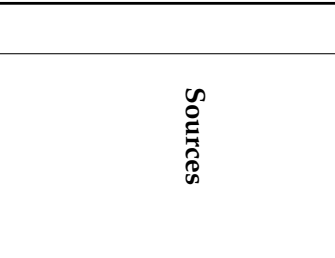 } & \multicolumn{3}{|c|}{ Road Geometry } & \multicolumn{2}{|c|}{ Pavement Marking } & \multicolumn{3}{|c|}{ Weather Condition } & \multirow[t]{2}{*}{ Speed } \\
\hline & 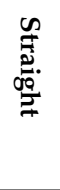 & 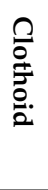 & 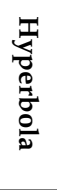 & 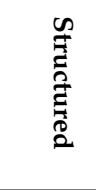 & 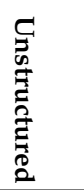 & 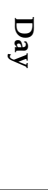 & 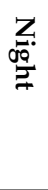 & $\begin{array}{l}\text { च. } \\
\text { : }\end{array}$ & \\
\hline [75] Liu \& Li et al. (2018) & $\sqrt{ }$ & - & $\sqrt{ }$ & $\sqrt{ }$ & - & $\sqrt{ }$ & $\sqrt{ }$ & $\sqrt{ }$ & - \\
\hline [76] Han et al. (2019) & $\sqrt{ }$ & - & - & $\sqrt{ }$ & $\sqrt{ }$ & $\sqrt{ }$ & - & - & $30-50 \mathrm{~km} / \mathrm{h}$ \\
\hline [77] Tominaga et al. (2019) & - & - & - & $\sqrt{ }$ & - & $\sqrt{ }$ & - & - & $80 \mathrm{~km} / \mathrm{h}$ \\
\hline [78] Chen Z et al. (2019) & $\sqrt{ }$ & - & $\sqrt{ }$ & $\sqrt{ }$ & - & - & - & - & - \\
\hline [79] Feng et al. (2019) & $\sqrt{ }$ & - & $\sqrt{ }$ & $\sqrt{ }$ & - & $\sqrt{ }$ & $\sqrt{ }$ & $\sqrt{ }$ & $120 \mathrm{~km} / \mathrm{h}$ \\
\hline
\end{tabular}

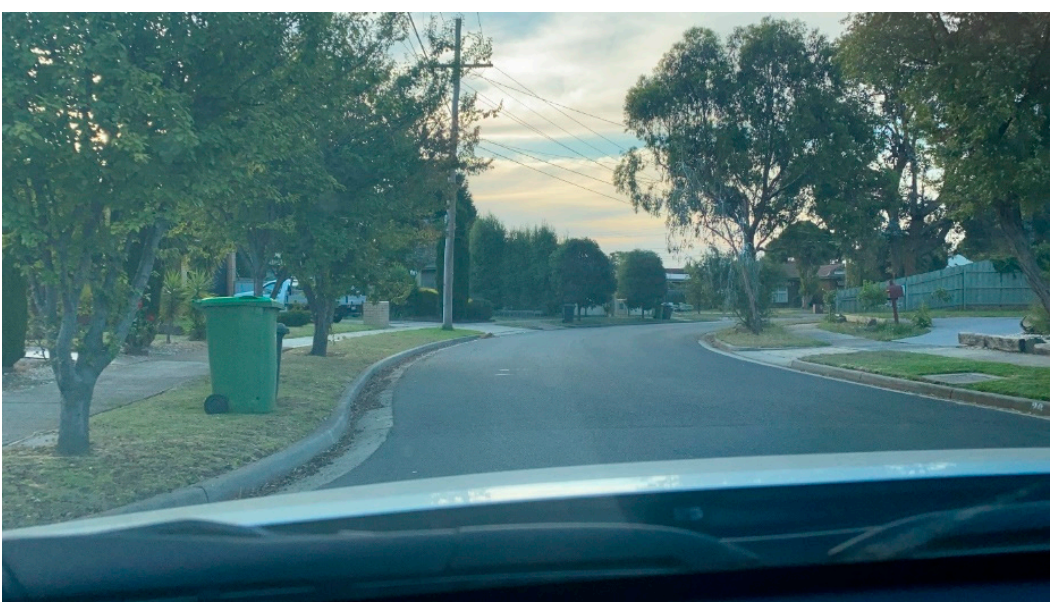

Figure 3. Efficiency of the unstructured road is affected by shadow, heavy rain, low or high illumination.

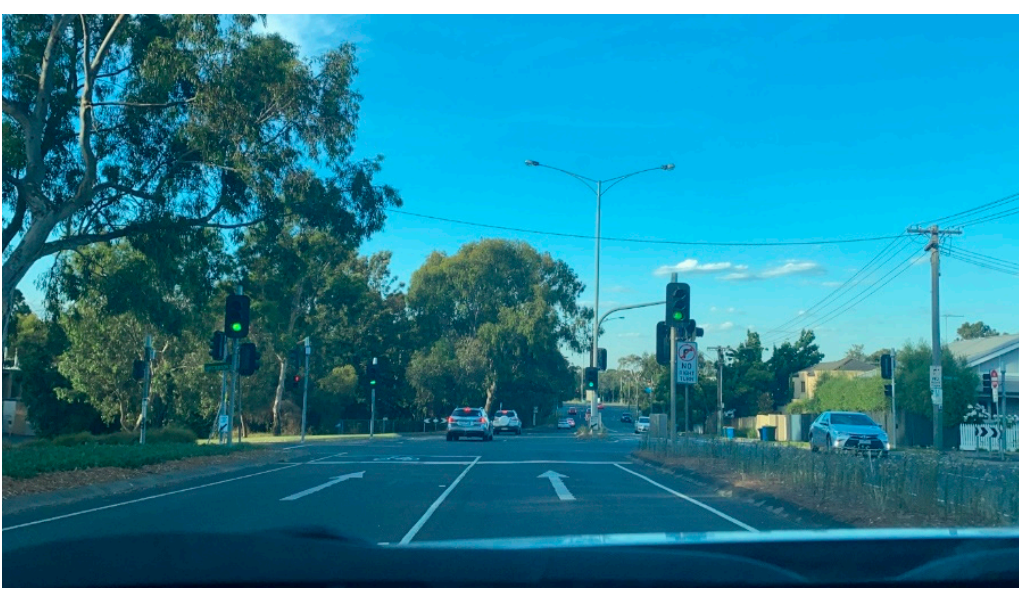

Figure 4. Challenge in lane marking detection: vehicle stop or occlude nearby lane.

Lane markings are usually yellow and white, although reflector lanes are designated with other colors. The number of lanes and their width varies per country. Due to the existence of shadows, there may be problems with vision clarity. The surrounding cars may obstruct the lane markings. Likewise, there is a dramatic shift in lighting as the car exits a tunnel. As a result, excessive light has an impact on visual clarity. Due to different weather conditions such as rain, fog, and snow, the visibility of the lane markings decreases. In the evening, visibility may be reduced. These difficulties in lane recognition and tracking 
lead to a drop in the performance of lane detection and tracking algorithms. Therefore, the development of a reliable lane detecting system is a challenge.

\section{Conclusions}

Over the last decade, many researchers have researched ADAS. This field continues to grow, as fully autonomous vehicles are predicted to enter the market soon $[80,81]$. There are limited studies in the literature that provides the state-of-art in lane detection and tracking algorithms and evaluation of the algorithms. To fulfil this gap, in this study, we have provided a comprehensive review of different methods of lane detection and tracking algorithms. In addition, we presented a summary of different data sets that researchers have used to test the algorithms, along with the approaches for evaluating the performance of the algorithms. Further, a summary of patented works has also been provided.

The use of a Learning-based approach is gaining popularity because it is computationally more efficient and provides reasonable results in real-time scenarios. The unavailability of rigorous and varied datasets to test the algorithms have been a constraint to the researchers. However, using synthetic sensor data generated by using a test vehicle or driving scenario through a vehicle simulator app availability in commercial software has opened the door for testing algorithms. Likewise, the following areas need more investigations in future:

- lane detection and tracking under different complex geometric road design models, e.g., hyperbola and clothoid

- achieving high reliability for detecting and tracking the lane under different weather conditions, different speeds and weather conditions, and

- lane detection and tracking for the unstructured roads

This study aimed to comprehensively review previous literature on lane detection and tracking for ADAS and identify gaps in knowledge for future research. This is important because limited studies provide state-of-art lane detection and tracking algorithms for ADAS and a holistic overview of works in this area. The quantitative assessment of mathematical models and parameters is beyond the scope of this work. It is anticipated that this review paper will be a valuable resource for the researchers intending to develop reliable lane detection and tracking algorithms for emerging autonomous vehicles in future.

Author Contributions: Investigation, data collection, methodology, writing-original draft preparation, S.W.; Supervision, writing-review and editing, N.S.; Supervision, writing-review and editing, P.S. All authors have read and agreed to the published version of the manuscript.

Funding: This research received no external funding.

Institutional Review Board Statement: Not applicable.

Informed Consent Statement: Not applicable.

Data Availability Statement: Not applicable.

Acknowledgments: The first author would like to acknowledge the Government of India, Ministry of Social Justice \& Empowerment, for providing full scholarship to pursue PhD study at RMIT University. We want to thank the three anonymous reviewers whose constructive comments helped to improve the paper further.

Conflicts of Interest: The authors declare no conflict of interest.

\section{References}

1. Nilsson, N.J. Shakey the Robot; Sri International Menlo Park: California, CA, USA, 1984.

2. Tsugawa, S.; Yatabe, T.; Hirose, T.; Matsumoto, S. An Automobile with Artificial Intelligence. In Proceedings of the 6th International Joint Conference on Artificial Intelligence, Tokyo, Japan, 20 August 1979.

3. Blackman, C.P. The ROVA and MARDI projects. In Proceedings of the IEEE Colloquium on Advanced Robotic Initiatives in the UK, London, UK, 17 April 1991; pp. 5/1-5/3. 
4. Thorpe, C.; Herbert, M.; Kanade, T.; Shafter, S. Toward autonomous driving: The CMU Navlab. II. Architecture and systems. IEEE Expert. 1991, 6, 44-52. [CrossRef]

5. Horowitz, R.; Varaiya, P. Control design of an automated highway system. Proc. IEEE 2000, 88, 913-925. [CrossRef]

6. Pomerleau, D.A.; Jochem, T. Rapidly Adapting Machine Vision for Automated Vehicle Steering. IEEE Expert. 1996, $11,19-27$. [CrossRef]

7. Parent, M. Advanced Urban Transport: Automation Is on the Way. Intell. Syst. IEEE 2007, 22, 9-11. [CrossRef]

8. Lari, A.Z.; Douma, F.; Onyiah, I. Self-Driving Vehicles and Policy Implications: Current Status of Autonomous Vehicle Development and Minnesota Policy Implications. Minn. J. Law Sci. Technol. 2015, 16, 735.

9. Urmson, C. Green Lights for Our Self-Driving Vehicle Prototypes. Available online: https://blog.google/alphabet/self-drivingvehicle-prototypes-on-road/ (accessed on 30 September 2021).

10. Campisi, T.; Severino, A.; Al-Rashid, M.A.; Pau, G. The Development of the Smart Cities in the Connected and Autonomous Vehicles (CAVs) Era: From Mobility Patterns to Scaling in Cities. Infrastructures 2021, 6, 100. [CrossRef]

11. Severino, A.; Curto, S.; Barberi, S.; Arena, F.; Pau, G. Autonomous Vehicles: An Analysis both on Their Distinctiveness and the Potential Impact on Urban Transport Systems. Appl. Sci. 2021, 11, 3604. [CrossRef]

12. Aly, M. Real time Detection of Lane Markers in Urban Streets. In Proceedings of the 2008 IEEE Intelligent Vehicles Symposium, Eindhoven, The Netherlands, 4-6 June 2008; pp. 7-12. [CrossRef]

13. Bar Hillel, A.; Lerner, R.; Levi, D.; Raz, G. Recent progress in road and lane detection: A survey. Mach. Vis. Appl. 2014, 25, 727-745. [CrossRef]

14. Ying, Z.; Li, G.; Zang, X.; Wang, R.; Wang, W. A Novel Shadow-Free Feature Extractor for Real-Time Road Detection. In Proceedings of the 24th ACM International Conference on Multimedia, Amsterdam, The Netherlands, 15-19 October 2016.

15. Jothilashimi, S.; Gudivada, V. Machine Learning Based Approach. 2016. Available online: https://www.sciencedirect.com/ topics / computer-science/machine-learning-based-approach (accessed on 20 August 2021).

16. Zhou, S.; Jiang, Y.; Xi, J.; Gong, J.; Xiong, G.; Chen, H. A novel lane detection based on geometrical model and Gabor filter. In Proceedings of the 2010 IEEE Intelligent Vehicles Symposium, La Jolla, CA, USA, 21-24 June 2010; pp. 59-64.

17. Zhao, H.; Teng, Z.; Kim, H.; Kang, D. Annealed Particle Filter Algorithm Used for Lane Detection and Tracking. J. Autom. Control Eng. 2013, 1, 31-35. [CrossRef]

18. Paula, M.B.; Jung, C.R. Real-Time Detection and Classification of Road Lane Markings. In Proceedings of the 2013 XXVI Conference on Graphics, Patterns and Images, Arequipa, Peru, 5-8 August 2013.

19. Kukkala, V.K.; Tunnell, J.; Pasricha, S.; Bradley, T. Advanced Driver-Assistance Systems: A Path toward Autonomous Vehicles. In IEEE Consumer Electronics Magazine; IEEE: Eindhoven, The Netherlands, 2018; Volume 7, pp. 18-25. [CrossRef]

20. Yenkanchi, S. Multi Sensor Data Fusion for Autonomous Vehicles; University of Windsor: Windsor, ON, Canada, 2016.

21. Synopsys.com. What Is ADAS (Advanced Driver Assistance Systems)?-Overview of ADAS Applications I Synopsys. 2021. Available online: https:/ / www.synopsys.com/automotive/what-is-adas.html (accessed on 12 October 2021).

22. McCall, J.C.; Trivedi, M.M. Video-based lane estimation and tracking for driver assistance: Survey, system, and evaluation. In IEEE Transactions on Intelligent Transportation Systems; IEEE: Eindhoven, The Netherlands, 2006; Volume 7, pp. 20-37. [CrossRef]

23. Veit, T.; Tarel, J.; Nicolle, P.; Charbonnier, P. Evaluation of Road Marking Feature Extraction. In Proceedings of the 2008 11th International IEEE Conference on Intelligent Transportation Systems, Beijing, China, 12-15 October 2008; pp. $174-181$.

24. Kuo, C.Y.; Lu, Y.R.; Yang, S.M. On the Image Sensor Processing for Lane Detection and Control in Vehicle Lane Keeping Systems. Sensors 2019, 19, 1665. [CrossRef]

25. Kang, C.M.; Lee, S.H.; Kee, S.C.; Chung, C.C. Kinematics-based Fault-tolerant Techniques: Lane Prediction for an Autonomous Lane Keeping System. Int. J. Control Autom. Syst. 2018, 16, 1293-1302. [CrossRef]

26. Borkar, A.; Hayes, M.; Smith, M.T. Robust lane detection and tracking with ransac and Kalman filter. In Proceedings of the 2009 16th IEEE International Conference on Image Processing (ICIP), Cairo, Egypt, 7-10 November 2009; pp. 3261-3264. [CrossRef]

27. Sun, Y.; Li, J.; Sun, Z. Multi-Stage Hough Space Calculation for Lane Markings Detection via IMU and Vision Fusion. Sensors 2019, 19, 2305. [CrossRef]

28. Lu, J.; Ming Yang, M.; Wang, H.; Zhang, B. Vision-based real-time road detection in urban traffic, Proc. SPIE 4666. In Real-Time Imaging VI; SPIE: Bellingham, WA, USA, 2002. [CrossRef]

29. Zhang, X.; Shi, Z. Study on lane boundary detection in night scene. In Proceedings of the 2009 IEEE Intelligent Vehicles Symposium, Xi'an, China, 3-5 June 2009; pp. 538-541. [CrossRef]

30. Borkar, A.; Hayes, M.; Smith, M.T.; Pankanti, S. A layered approach to robust lane detection at night. In Proceedings of the 2009 IEEE Workshop on Computational Intelligence in Vehicles and Vehicular Systems, Nashville, TN, USA, 30 March-2 April 2009; pp. 51-57. [CrossRef]

31. Priyadharshini, P.; Niketha, P.; Saantha Lakshmi, K.; Sharmila, S.; Divya, R. Advances in Vision based Lane Detection Algorithm Based on Reliable Lane Markings. In Proceedings of the 2019 5th International Conference on Advanced Computing \& Communication Systems (ICACCS), Coimbatore, India, 15-16 March 2019; pp. 880-885. [CrossRef]

32. Hong, G.-S.; Kim, B.-G.; Dorra, D.P.; Roy, P.P. A Survey of Real-time Road Detection Techniques Using Visual Color Sensor. J. Multimed. Inf. Syst. 2018, 5, 9-14. [CrossRef]

33. Park, H. Implementation of Lane Detection Algorithm for Self-driving Vehicles Using Tensor Flow. In International Conference on Innovative Mobile and Internet Services in Ubiquitous Computing; Springer: Cham, Switzerland, 2018; pp. $438-447$. 
34. El Hajjouji, I.; Mars, S.; Asrih, Z.; Mourabit, A.E. A novel FPGA implementation of Hough Transform for straight lane detection. Eng. Sci. Technol. Int. J. 2020, 23, 274-280. [CrossRef]

35. Samadzadegan, F.; Sarafraz, A.; Tabibi, M. Automatic Lane Detection in Image Sequences for Vision-based Navigation Purposes. ISPRS Image Eng. Vis. Metrol. 2006. Available online: https://www.semanticscholar.org/paper/Automatic-Lane-Detection-inImage-Sequences-for-Samadzadegan-Sarafraz/55f0683190eb6cb21bf52c5f64b443c6437b38ea (accessed on 12 August 2021).

36. Cheng, H.-Y.; Yu, C.-C.; Tseng, C.-C.; Fan, K.-C.; Hwang, J.-N.; Jeng, B.-S. Environment classification and hierarchical lane detection for structured and unstructured roads. Comput. Vis. IET 2010, 4, 37-49. [CrossRef]

37. Han, J.; Kim, D.; Lee, M.; Sunwoo, M. Road boundary detection and tracking for structured and unstructured roads using a 2D lidar sensor. Int. J. Automot. Technol. 2014, 15, 611-623. [CrossRef]

38. Le, M.C.; Phung, S.L.; Bouzerdoum, A. Lane Detection in Unstructured Environments for Autonomous Navigation Systems. In Asian Conference on Computer Vision; Cremers, D., Reid, I., Saito, H., Yang, M.H., Eds.; Springer: Cham, Switzerland, 2015. [CrossRef]

39. Wang, J.; Ma, H.; Zhang, X.; Liu, X. Detection of Lane Lines on Both Sides of Road Based on Monocular Camera. In Proceedings of the 2018 IEEE International Conference on Mechatronics and Automation (ICMA), Changchun, China, 5-8 August 2018; pp. 1134-1139.

40. YenIaydin, Y.; Schmidt, K.W. Sensor Fusion of a Camera and 2D LIDAR for Lane Detection. In Proceedings of the 2019 27th Signal Processing and Communications Applications Conference (SIU), Sivas, Turkey, 24-26 April 2019; pp. 1-4.

41. Kemsaram, N.; Das, A.; Dubbelman, G. An Integrated Framework for Autonomous Driving: Object Detection, Lane Detection, and Free Space Detection. In Proceedings of the 2019 Third World Conference on Smart Trends in Systems Security and Sustainablity (WorldS4), London, UK, 30-31 July 2019; pp. 260-265. [CrossRef]

42. Lee, C.; Moon, J.-H. Robust Lane Detection and Tracking for Real-Time Applications. IEEE Trans. Intell. Transp. Syst. 2018, 19, 1-6. [CrossRef]

43. Son, Y.; Lee, E.S.; Kum, D. Robust multi-lane detection and tracking using adaptive threshold and lane classification. Mach. Vis. Appl. 2018, 30, 111-124. [CrossRef]

44. Li, Q.; Zhou, J.; Li, B.; Guo, Y.; Xiao, J. Robust Lane-Detection Method for Low-Speed Environments. Sensors 2018, $18,4274$. [CrossRef]

45. Son, J.; Yoo, H.; Kim, S.; Sohn, K. Real-time illumination invariant lane detection for lane departure warning system. Expert Syst. Appl. 2014, 42. [CrossRef]

46. Chae, H.; Jeong, Y.; Kim, S.; Lee, H.; Park, J.; Yi, K. Design and Vehicle Implementation of Autonomous Lane Change Algorithm based on Probabilistic Prediction. In Proceedings of the 2018 21st International Conference on Intelligent Transportation Systems (ITSC), Maui, HI, USA, 4-7 November 2018; pp. 2845-2852. [CrossRef]

47. Chen, P.R.; Lo, S.Y.; Hang, H.M.; Chan, S.W.; Lin, J.J. Efficient Road Lane Marking Detection with Deep Learning. In Proceedings of the 2018 IEEE 23rd International Conference on Digital Signal Processing (DSP), Shanghai, China, 19-21 November 2018; pp. $1-5$.

48. Lu, Z.; Xu, Y.; Shan, X. A lane detection method based on the ridge detector and regional G-RANSAC. Sensors 2019, 19, 4028. [CrossRef]

49. Bian, Y.; Ding, J.; Hu, M.; Xu, Q.; Wang, J.; Li, K. An Advanced Lane-Keeping Assistance System with Switchable Assistance Modes. IEEE Trans. Intell. Transp. Syst. 2019, 21, 385-396. [CrossRef]

50. Wang, G.; Hu, J.; Li, Z.; Li, L. Cooperative Lane Changing via Deep Reinforcement Learning. arXiv 2019, arXiv:1906.08662.

51. Wang, P.; Chan, C.Y.; de La Fortelle, A. A reinforcement learning based approach for automated lane change maneuvers. In Proceedings of the 2018 IEEE Intelligent Vehicles Symposium (IV), Changshu, China, 26-30 June 2018; pp. 1379-1384.

52. Suh, J.; Chae, H.; Yi, K. Stochastic model-predictive control for lane change decision of automated driving vehicles. IEEE Trans. Veh. Technol. 2018, 67, 4771-4782. [CrossRef]

53. Gopalan, R.; Hong, T.; Shneier, M.; Chellappa, R. A learning approach towards detection and tracking of lane markings. IEEE Trans. Intell. Transp. Syst. 2012, 13, 1088-1098. [CrossRef]

54. Mueter, M.; Zhao, K. Method for Lane Detection. US20170068862A1. 2015. Available online: https://patents.google.com/patent/ US20170068862A1/en (accessed on 12 August 2021).

55. Joshi, A. Method for Generating Accurate Lane Level Maps. US9384394B2. 2013. Available online: https://patents.google.com/ patent/US9384394B2/en (accessed on 12 August 2021).

56. Kawazoe, H. Lane Tracking Control System for Vehicle. US20020095246A1. 2001. Available online: https://patents.google.com/ patent/US20020095246 (accessed on 12 August 2021).

57. Lisaka, A. Lane Detection Sensor and Navigation System Employing the Same. EP1143398A3. 1996. Available online: https: / / patents.google.com/patent/EP1143398A3/en (accessed on 12 August 2021).

58. Zhitong, H.; Yuefeng, Z. Vehicle Detecting Method Based on Multi-Target Tracking and Cascade Classifier Combination. CN105205500A. 2015. Available online: https:/ / patents.google.com/patent/CN105205500A/en (accessed on 12 August 2021).

59. Fujii, S. Steering Support Device. JP6589941B2, 2019. Patentimages.storage.googleapis.com. 2021. Available online: https: // patentimages.storage.googleapis.com/0b/d0/ff/978af5acfb7b35/JP6589941B2.pdf (accessed on 12 August 2021).

60. Gurghian, A.; Koduri, T.; Nariyambut Murali, V.; Carey, K. Lane Detection Systems and Methods. US10336326B2. 2016. Available online: https:/ / patents.google.com/patent/US10336326B2/en (accessed on 12 August 2021). 
61. Zhang, W.; Wang, J.; Lybecker, K.; Piasecki, J.; Brian Litkouhi, B.; Frakes, R. Enhanced Perspective View Generation in a Front Curb Viewing System Abstract. US9834143B2. 2014. Available online: https://patents.google.com/patent/US9834143B2/en (accessed on 12 August 2021).

62. Vallespi-Gonzalez, C. Object Detection for an Autonomous Vehicle. US20170323179A1. 2016. Available online: https:/ patents. google.com/patent/US20170323179A1/en (accessed on 12 August 2021).

63. Cu Lane Dataset. Available online: https://xingangpan.github.io/projects/CULane.html (accessed on 13 April 2020).

64. Caltech Pedestrian Detection Benchmark. Available online: http://www.vision.caltech.edu/Image_Datasets/CaltechPedestrians/ (accessed on 13 April 2020).

65. Lee, E. Digital Image Media Lab. Diml.yonsei.ac.kr. 2020. Available online: http://diml.yonsei.ac.kr/dataset/ (accessed on 13 April 2020).

66. Cvlibs.net. The KITTI Vision Benchmark Suite. Available online: http:/ /www.cvlibs.net/datasets/kitti/ (accessed on 27 April 2020).

67. Tusimple/Tusimple-Benchmark. Available online: https://github.com/TuSimple/tusimple-benchmark/tree/master/doc/ velocity_estimation (accessed on 15 April 2020).

68. Romera, E.; Luis, M.; Arroyo, L. Need Data for Driver Behavior Analysis? Presenting the Public UAH-Drive Set. In Proceedings of the 2016 IEEE 19th International Conference on Intelligent Transportation Systems, Rio de Janeiro, Brazil, 1-4 November 2016.

69. BDD100K Dataset. Available online: https://mc.ai/bdd100k-dataset/ (accessed on 2 April 2020).

70. Kumar, A.M.; Simon, P. Review of Lane Detection and Tracking Algorithms in Advanced Driver Assistance System. Int. J. Comput. Sci. Inf. Technol. 2015, 7, 65-78. [CrossRef]

71. Hamed, T.; Kremer, S. Computer and Information Security Handbook, 3rd ed.; Elesevier: Amsterdam, The Netherlands, 2017 ; p. 114.

72. Precision and Recall. Available online: https://en.wikipedia.org/wiki/Precision_and_recall (accessed on 13 January 2021).

73. Fiorentini, N.; Losa, M. Long-Term-Based Road Blackspot Screening Procedures by Machine Learning Algorithms. Sustainability 2020, 12, 5972. [CrossRef]

74. Wu, S.J.; Chiang, H.H.; Perng, J.W.; Chen, C.J.; Wu, B.F.; Lee, T.T. The heterogeneous systems integration design and implementation for lane keeping on a vehicle. IEEE Trans. Intell. Transp. Syst. 2008, 9, 246-263. [CrossRef]

75. Liu, H.; Li, X. Sharp Curve Lane Detection for Autonomous Driving. Comput. Sci. Eng. 2019, 21, 80-95. [CrossRef]

76. Han, J.; Yang, Z.; Hu, G.; Zhang, T.; Song, J. Accurate and robust vanishing point detection method in unstructured road scenes. J. Intell. Robot. Syst. 2019, 94, 143-158. [CrossRef]

77. Tominaga, K.; Takeuchi, Y.; Tomoki, U.; Kameoka, S.; Kitano, H.; Quirynen, R.; Berntorp, K.; Di Cairano, S. GNSS Based Lane Keeping Assist System via Model Predictive Control. 2019. Available online: https://doi.org/10.4271/2019-01-0685 (accessed on 9 September 2021).

78. Chen, Z.; Liu, Q.; Lian, C. PointLaneNet: Efficient end-to-end CNNs for Accurate Real-Time Lane Detection. In Proceedings of the 2019 IEEE Intelligent Vehicles Symposium (IV), Paris, France, 9-12 June 2019; pp. 2563-2568. [CrossRef]

79. Feng, Y.; Rong-ben, W.; Rong-hui, Z. Research on Road Recognition Algorithm Based on Structure Environment for ITS. In Proceedings of the 2008 ISECS International Colloquium on Computing, Communication, Control, and Management, Guangzhou, China, 3-4 August 2008; pp. 84-87. [CrossRef]

80. Nieuwenhuijsen, J.; de Almeida Correia, G.H.; Milakis, D.; van Arem, B.; van Daalen, E. Towards a quantitative method to analyze the long-term innovation diffusion of automated vehicles technology using system dynamics. Transp. Res. Part C Emerg. Technol. 2018, 86, 300-327. [CrossRef]

81. Stasinopoulos, P.; Shiwakoti, N.; Beining, M. Use-stage life cycle greenhouse gas emissions of the transition to an autonomous vehicle fleet: A System Dynamics approach. J. Clean. Prod. 2021, 278, 123447. [CrossRef] 